Research Article

\title{
Movement Laws of Overlying Strata above a Fully Mechanized Coal Mining Face Backfilled with Gangue: A Case Study in Jiulishan Coal Mine in Henan Province, China
}

\author{
Zhengkai Yang, ${ }^{1,2}$ Zhiheng Cheng $\mathbb{D}^{3,4}{ }^{3,4}$ Zhenhua Li $\mathbb{D}^{5}{ }^{5}$ Chunyuan Li, ${ }^{6}$ Lei Wang, \\ Shuaifeng Yin, ${ }^{3}$ and Jinhu Zhang \\ ${ }^{1}$ School of Energy and Mining Engineering, China University of Mining Technology-Beijing, Beijing 100083, China \\ ${ }^{2}$ China Coal Research Institute, Beijing 100013, China \\ ${ }^{3}$ North China Institute of Science \& Technology, Beijing 100013, China \\ ${ }^{4}$ NCIST Zhongan Technology (Beijing) Co., Ltd., Beijing 101601, China \\ ${ }^{5}$ School of Energy Science and Engineering, Henan Polytechnic University, Jiaozuo, Henan 454000, China \\ ${ }^{6}$ Deep Mining and Rock Burst Research Institute, China Academy of Coal Science, Beijing 100013, China \\ ${ }^{7}$ China Coal Society, Beijing 101601, China \\ ${ }^{8}$ CCTEG Coal Mining Research Institute, Coal Mining Branch, China Coal Research Institute, Beijing 100013, China
}

Correspondence should be addressed to Zhiheng Cheng; an958158@163.com and Zhenhua Li; jzlizhenh@163.com

Received 8 March 2021; Accepted 20 April 2021; Published 24 May 2021

Academic Editor: Dezhong Kong

Copyright $\odot 2021$ Zhengkai Yang et al. This is an open access article distributed under the Creative Commons Attribution License, which permits unrestricted use, distribution, and reproduction in any medium, provided the original work is properly cited.

The aim of this study is to obtain movement laws of overlying strata above a fully mechanized coal mining face backfilled with gangue and solve the problem of surface subsidence during coal mining. This study was carried out based on gangue backfilling mining of Jiulishan Coal Mine (Jiaozuo City, Henan Province, China) from the perspectives of deformation of backfilled gangue under compaction, surrounding rock of a stope, and activities of key strata. The method combining with rock mechanics, viscoelastic mechanics, control theory of rock mass under mining, and numerical simulation was used based on physical and mechanical characteristics of backfilled gangue. On this basis, the research analyzed the temporal-spatial relationships of activities of surrounding rock of the stope, compressive deformation of backfilling body, failure depth of the floor, deformation characteristics of the main roof with laws of surface subsidence. The movement characteristics of overlying strata above the fully mechanized coal mining face backfilled with gangue and the traditional fully mechanized mining face were compared. It is found that, under the same conditions of overlying strata, movement laws of overlying strata are mainly determined by the mining height of coal seams and the heights of a caving zone and a fracture zone are nearly linearly correlated with the mining height. Through analysis based on thin-plate theory and key stratum theory, the location of the main roof of the fully mechanized coal mining face backfilled with gangue in coal seams first bending and sinking due to load of overlying strata was ascertained. Then, it was determined that there are two key strata and the main roof belongs to the inferior key stratum. By using the established mechanical model for the main roof of the fully mechanized coal mining face backfilled with gangue and the calculation formula for the maximum deflection of the main roof, this research presented the conditions for breaking of the main roof. In addition, based on the theoretical analysis, it is concluded that the main roof of the fully mechanized coal mining face backfilled with gangue does not break, but bends. The numerical simulation results demonstrate that, with the continuous increase of strength of backfilled gangue, the stress concentration degree of surrounding rock reduces constantly, so does its decrease amplitude. Moreover, the compressive deformation of backfilling, failure depth of the floor, and bending and subsidence of the main roof continuously decrease and tend to be stable. The mechanical properties of backfilling materials determine effects of gangue backfilling in controlling surface subsidence. Gangue backfilling can effectively control movement of overlying strata and surface subsidence tends to be stable with the increase of elastic modulus of gangue. 


\section{Introduction}

Coalbed methane development, groundwater exploitation, and mineral exploitation are main factors leading to surface subsidence; particularly, surface subsidence is more obvious in the case of full-seam mining or mining with a large mining height (Figure 1). The main influences of coal seam mining on the surface are characterized by surface subsidence and large cracks on the surface. This leads to surface subsidence, landslide, and damage to farmland, houses, and roads. In particular, surface subsidence caused by coal mining usually occurs in the form of surface collapse. Surface collapse refers to a phenomenon of sudden surface subsidence to form small or large sinkholes or pits, which poses a particularly great threat to landscape and human life, because there is no premonitory phenomenon before it occurs. It can cause many harms, such as surface change, landslide of steep cliffs, and damage to farmland, houses, and roads [1-14].

At present, a lot of research has been conducted on the prediction, characteristics, mechanisms, and control methods of surface subsidence, and a variety of methods have been developed [15-20]. However, their performances in backfilling and subsidence control are quite different [21-26]. So far, a large number of attempts have been made in the world to fully understand the surface subsidence process. These attempts mainly focus on the characteristics, prediction methods, mechanisms, and control measures of surface subsidence [27-44] and most of the studies are based on the continuity assumption. In the meanwhile, the overlying strata in the western China are relatively thin and buried between $221 \mathrm{~m}$ and $375 \mathrm{~m}$ underground. Without stopping and backfilling, the surface subsidence and damage will be more obvious. Based on the requirements of environmental protection and sustainable development of mines, the backfilling mining technology develops rapidly [4]. According to incomplete statistics, the amount of coal mining under buildings, railways, and water-bodies of production mines is up to $1.43 \times 10^{10} t[1]$ and the cumulative amount of gangue piled up over the years in China is about $4.5 \times 10^{9} t$. Moreover, there are more than 1,600 gangue dumps on the surface of coal mines in China, occupying a land area of $1.5 \times 10^{4} \mathrm{hm}^{2}[1,4,6]$, so gangue has become the main hazard source of environmental pollution in mines $[2,3,7,45]$. Therefore, scholars in China put forward the scientific mining concept of developing green mining technologies [5], including the coal mining technology for coal mining under buildings, railways, and water-bodies by directly backfilling solid wastes (gangue, fly ash, loess, yellow sand, etc.) in mining areas $[4,16]$. Miao $[4,15,16]$ systematically introduced the research progress of fully mechanized solid backfilling mining technology and mainly discussed the control theory of strata movement during backfilling mining with dense backfilling body. The theoretical breakthrough is the premise of developing new technologies, mainly including the equivalent mining height theory for controlling strata movement during backfilling mining, the continuous medium mechanics model and the calculation formula for strata movement during backfilling mining, and analysis on mine pressure in a stope and support stress during solid backfilling. Therefore, the compactness of backfilling materials is the key factor controlling strata movement in the backfilling mining face. By experimentally studying different filling media, Liu and Qingbiao [46] basically mastered the reasonable mixing ratio of filling materials and mechanical properties, such as compactness, rheology, and weathering characteristics of various filling materials. Based on the analysis of the moving characteristics of the roof during fully mechanized backfilling mining, Zhang et al. [23] established the mechanical model of key blocks in the main roof during fully mechanized mining backfilling. According to the deformation law under compaction of waste fillings and cracked immediate roof, they deduced the relational expression of mechanics of support strength in the backfilled fully mechanized coal mining face. The study proves the feasibility of gangue backfilling mining and concludes the law of strata behaviors in fully mechanized coal mining face backfilled with gangue through field application. In the meanwhile, based on the characteristics of strata movement of solid backfilling mining technology, Guo et al. [47] proposed the surface subsidence prediction method based on the equivalent mining height theory and described the parameter selection guideline of this method. While comparing the parameters of caving mining with equivalent height, the subsidence efficiency can be calculated according to the mining height and bulk factors of sagging zone and fracture zone. By conducting a field experiment in a Chinese coal mine located under thick unconsolidated layers, Wang et al. [48] proposed a backfilling strip mining method via determination of the appropriate longwall face length and mining height, to protect the bearing structure from being damaged, thus avoiding surface collapse. They found that no surface collapse occurred in the mining process. The research results indicate that the method can prevent surface collapse during longwall mining under thick unconsolidated layers. Zhao et al. built physical and numerical models for controlling backfill in steeply dipping coal seams to determine an optimum backfilling approach to control surface collapse. The physical modeling results show that, for mining without backfill, the thickness of the largest roof collapse is approximately twice that of the mined seams, the movement of roof strata tends to be asymmetrical, and there is a relatively large empty zone in the upper gob area. Numerical simulation results demonstrate that floor strata mainly undergo nearly horizontal displacement, while roof strata mainly experience vertical subsidence, either with or without backfilling. The integrity of roof strata is improved as the extent of backfilling increases and the range of displacement increases. The conclusions are proved by results from a field experiment. The similar simulation and field measurement are performed on movement laws of overlying strata above the working face backfilled with gangue, which provides a reliable theoretical basis for backfilling mining [21, 22]. By 


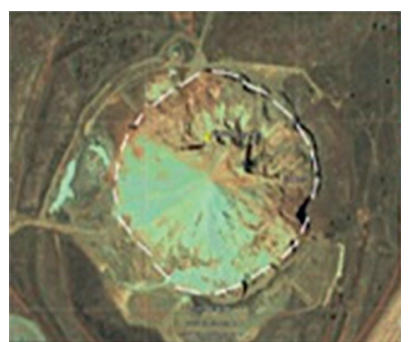

(a)

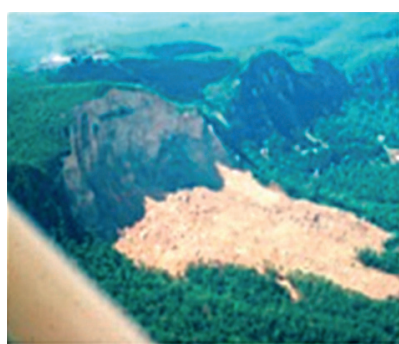

(b)

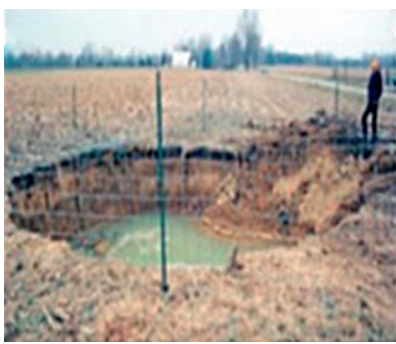

(c)

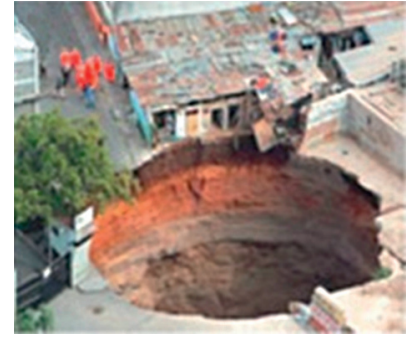

(d)

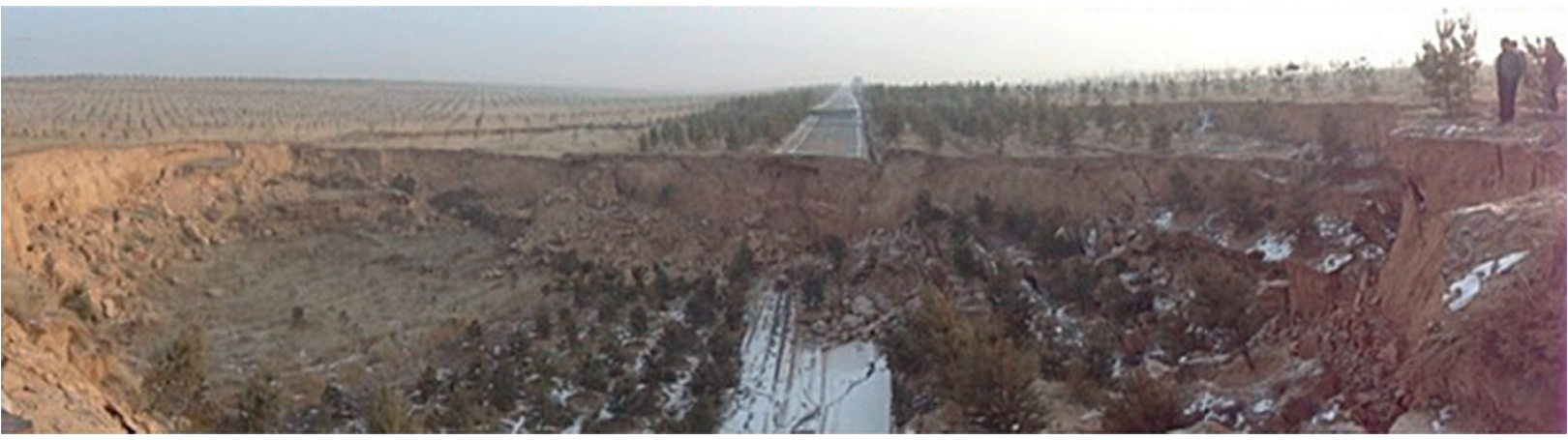

(e)

Figure 1: Problems caused by surface subsidence and surface cracks. (a) Surface subsidence in Australia; (b) landslide in Australia; (c) damage to farmland in India; (d) damage to roads in China.

using two test plans, the deformation and seepage test and the seepage test, Li et al. [49] compared and studied the permeable behaviors of gangue during the time related deformation process and obtained the permeability of gangue when the seepage is stable under each stress level. During gangue backfilling, physical and mechanical properties of gangue have important influences on displacement of overlying strata and surface subsidence and the effects of different types of gangue are not clear. Moreover, selecting appropriate gangue plays an important role in controlling surface subsidence.

In the process of gangue backfilling mining, the compaction and bearing of backfilling materials are particularly important, and the compressive deformation of backfilling materials directly affects the movement and deformation of the surface. However, little attention had been paid to stress distribution of overlying strata under gangue backfilling conditions, the influences of hierarchical optimization of particle size and elastic moduli of backfilled gangue. On this basis, this study firstly determined the stress distribution characteristics in a stope of a gangue backfilling face based on the thin-plate theory and then carried out a theoretical analysis to determine stress distribution characteristics in overlying strata. Secondly, key strata of the working face backfilled with gangue were determined and the deformation characteristics of the roof under mining were defined. Finally, this study analyzed gangue with different elastic moduli, clarified influences of mechanical parameters of gangue on surface subsidence, and determined reasonable physical and mechanical parameters of gangue.

\section{Overview of the Study Area}

At present, many development roadways in Jiulishan Coal Mine in Jiaozuo City, Henan Province, China, are being expanded and repaired. When taking measures for regional gas control, many rock roadways (at present, there are nearly 20 heading faces of rock roadways in the whole mine) need to be excavated, and the daily discharge of gangue reaches $1,400 t$, which leads to the busy auxiliary haulage systems in the mine. Jiulishan Coal Mine has accumulated nearly $9.4 \times 10^{5} \mathrm{~m}^{3}$ of gangue on the ground and at present, there is a serious shortage of gangue disposal sites. Mining with gangue backfilling technology not only makes lifting of existing gangue to the ground unnecessary and reduces the cost of gangue discharge, but also can consume the existing gangue on the ground and reduce costs for discharge, transportation and lifting of gangue and construction and maintenance of gangue discharge sites. This fundamentally solves the problem of land occupation and management of gangue dumps and greatly reduces environmental pollution in the coal mine. Based on this, taking Jiulishan Coal Mine as the research object, gangue excavated from the coal mine was used in the test. The physical and mechanical characteristics of gangue are shown in Table 1.

In the mining test with gangue backfilling, the 12031 working face, located in the north wing of No. 12 mining area of Jiulishan Coal Mine, was mined. No. 12 mining area was mined with backfilling in Jiulishan Coal Mine, with a mining area of $430,400 \mathrm{~m}^{2}$, geological reserve of $3.443 \times 10^{6} \mathrm{t}$, and the ground elevation of $+93 \mathrm{~m}$. The coal pillars were retained for protecting villages and industrial squares in this 
TABLE 1: Mechanical parameters of rock samples.

\begin{tabular}{lccccccc}
\hline Strata & $\begin{array}{c}\text { Compressive } \\
\text { strength }(\mathrm{MPa})\end{array}$ & $\begin{array}{c}\text { Elastic modulus } \\
(\mathrm{GPa})\end{array}$ & $\begin{array}{c}\text { Poisson's } \\
\text { ratio }\end{array}$ & $\begin{array}{c}\text { Cohesion } \\
(\mathrm{MPa})\end{array}$ & $\begin{array}{c}\text { Angle of } \\
\text { internal } \\
\text { friction }\left({ }^{\circ}\right)\end{array}$ & $\begin{array}{c}\text { Protodyakonov } \\
\text { coefficient }\end{array}$ & $\begin{array}{c}\text { Deformation } \\
\text { modulus }(\mathrm{GPa})\end{array}$ \\
\hline Sandstone & 5.90 & 69.80 & 0.16 & 39.48 & 35.30 & 9.30 & 9.20 \\
Mudstone & 3.25 & 38.90 & 0.21 & 47.09 & 29.20 & 5.58 & 7.40 \\
\hline
\end{tabular}

area. The layout of roadways in the fully mechanized coal mining face backfilled with gangue is displayed in Figure 2.

\section{Movement Characteristics of Overlying Strata above the Fully Mechanized Mining Face}

3.1. Movement Characteristics of Overlying Strata above the Traditional Fully Mechanized Mining Face. After the coal mining, the original stress equilibrium state around the goaf is damaged, inducing stress redistribution. As a result, this causes deformation, damage and movement of rock strata, which develops upwards to the surface to induce surface movement. Such a process and phenomenon is known as strata movement [3]. A large number of observations [2, 3] show that when the goaf is treated with the fully caving method, the goaf can be divided into three zones, namely, a caving zone, a fracture zone, and a bending zone, according to the degree of movement and damage of overlying strata therein. The schematic diagram of movement of overlying strata above the traditional fully mechanized mining face is demonstrated in Figure 3.

3.2. Movement Characteristics of Overlying Strata above the Fully Mechanized Coal Mining Face Backfilled with Gangue. The heights of the caving zone and fracture zone are related to lithology and the mining height of coal seams [2]. The harder the overlying strata of coal seams are, the smaller the heights of the caving zone and fracture zone are [46]. In accordance with the concept of equivalent mining height proposed by Professor Miao Xiexing, mining with gangue backfilling is equivalent to reducing the mining height. In other words, it is same as mining thin coal seams, which is equivalent to reducing the heights of the caving zone and fracture zone. For the fully mechanized working face mined by the technology of backfilling goaf with gangue, with the advance of the working face, the goaf is backfilled with gangue when the immediate roof does not cave. Because of bulking characteristics of gangue for backfilling and caved from the immediate roof, the goaf backfilled with gangue changes with time and the gangue backfilling body is compressed and deformed under load of overlying strata. The deformation of the gangue backfilling body is mainly elastic and plastic. The deformation of the gangue backfilling body leads to the caving of the main roof, which is in direct contact with the broken immediate roof. The soft strata borne by the main roof are gradually separated from the key strata after subsidence and the key strata bend and deform due to load of overlying strata. However, confined by the separation space, the key strata and their bearing body directly act on the soft layers below. With the increase of deformation, the supporting force provided by the lower soft layers is strengthened, thus limiting the bending deformation of the key strata [46]. The strata movement characteristics during fully mechanized mining with gangue backfilling are illustrated in Figure 4.

The heights of the caving zone and fracture zone have a correlation with factors, such as the mining height, dip angle of coal seams, and mining methods as well as lithology and structure of overlying strata. Due to different mining heights from the traditional fully mechanized mining face, movement laws of overlying strata above the fully mechanized coal mining face backfilled with gangue are mainly determined by the mining height of coal seams under the same conditions of overlying strata. The heights of the caving zone and fracture zone are nearly linearly related to the mining height [7]. Gangue backfilling greatly reduces the heights of the caving zone and fracture zone, which well controls movement of overlying strata and effectively prevents water inrush accidents in the working face, thus providing favorable conditions for safe mining of the working face.

\section{Stress Analysis on the Main Roof during Mining with Gangue Backfilling}

\subsection{Analysis of the Main Roof of the Fully Mechanized Coal Mining Face Backfilled with Gangue Based on Thin-Plate Theory}

4.1.1. Establishment of the Mechanical Model. The 12031 working face of Jiulishan Coal Mine is mined by gangue backfilling. The upper part of the working face has been a goaf, while the lower part contains unmined coal mass. The initial support conditions of the main roof of the stope are set as follows: it is fixed on three sides and simply supported on one side. Therefore, by using the mechanical model with the fixed support on three sides and simple support on one side (Figure 5(a)), the stress distribution and breaking laws of the roof of the working face backfilled with gangue were analyzed [2].

4.1.2. Stress Distribution Laws in the Roof of the Stope of the Working Face Backfilled with Gangue. Based on the mechanical model of the main roof of the stope of the 12031 working face in Jiulishan Coal Mine, stress analysis was conducted on the roof of the stope (Figure 5(b)). In accordance with the boundary conditions of the mechanical model of the roof with the fixed support on three sides and simple support on one side, the calculation formula for stress distribution in the main roof during gangue backfilling mining is shown as follows: 


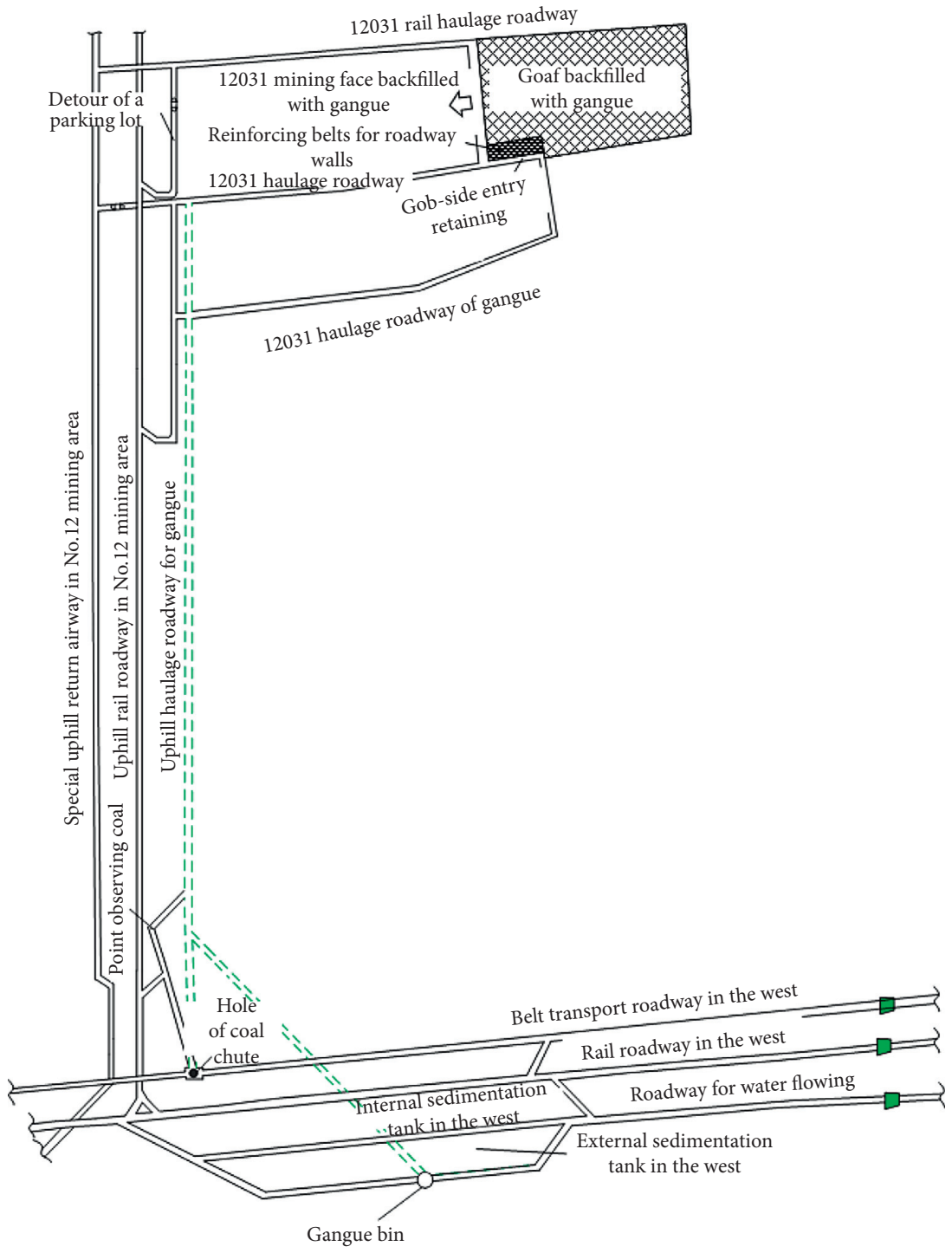

FIGURE 2: Diagram of layout of roadways in the fully mechanized coal mining face backfilled with gangue.

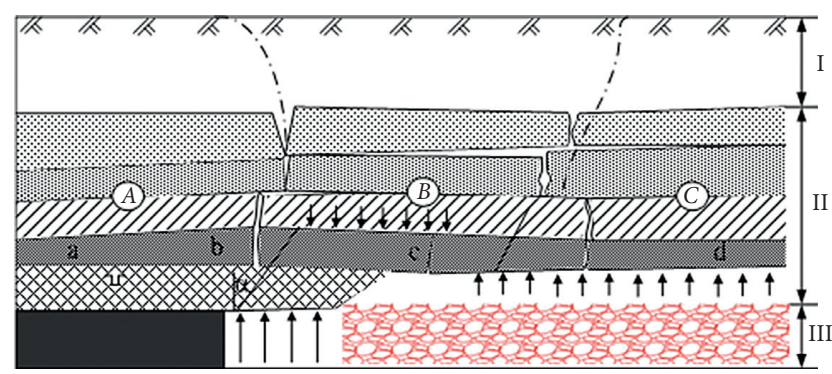

FIGURE 3: Schematic diagram of movement of overlying strata above the traditional fully mechanized mining face. A: zone affected by support of coal wall; B: bed-separation zone; C: recompacted zone; $\alpha$ represents the angle affected by support; I, II, and III indicate the bending and subsidence zone, the fracture zone, and the caving zone, respectively.

$$
\left\{\begin{array}{l}
\sigma_{x}=-\frac{2 \mathrm{EAz}}{b^{2}\left(1-\mu^{2}\right)}\left[1+\left(\frac{2 \pi^{2} \mu x^{2}}{a^{2}}-1\right) \cos \frac{2 \pi y}{a}\right] \\
\sigma_{y}=-\frac{2 \mathrm{EAz}}{b^{2}\left(1-\mu^{2}\right)}\left[\left(\frac{2 \pi^{2} x^{2}}{a^{2}}-\mu\right) \cos \frac{2 \pi y}{a}+\mu\right] \\
\tau_{x y}=-\frac{4 \mathrm{EAz} \pi x}{(1+\mu) \mathrm{ab}^{2}} \sin \frac{2 \pi y}{a}
\end{array}\right.
$$

where $\sigma_{x}, E, A$, and $b$ represent the normal stress ( $\mathrm{MPa}$ ) acting vertically on the $x$-axis plane, elastic modulus ( $\mathrm{MPa})$ of roof rock, coefficient of the deflection surface, and length (m) of the working face, respectively; $\mu, a$, and $\sigma_{y}$ indicate 


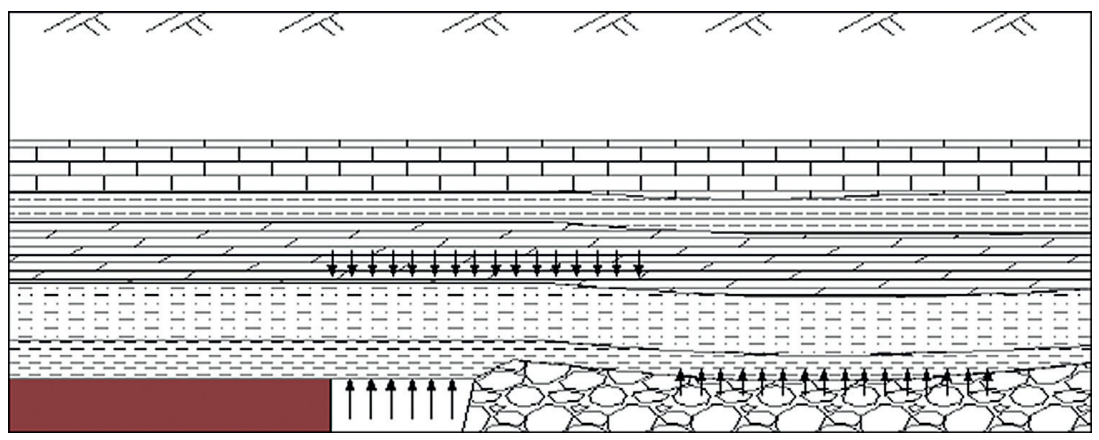

FIGURE 4: Schematic diagram of movement of overlying strata above the fully mechanized coal mining face backfilled with gangue.

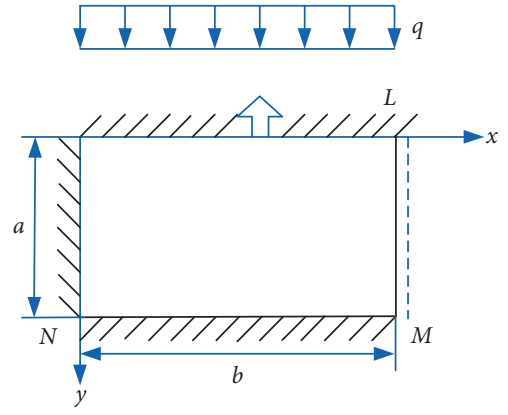

(a)

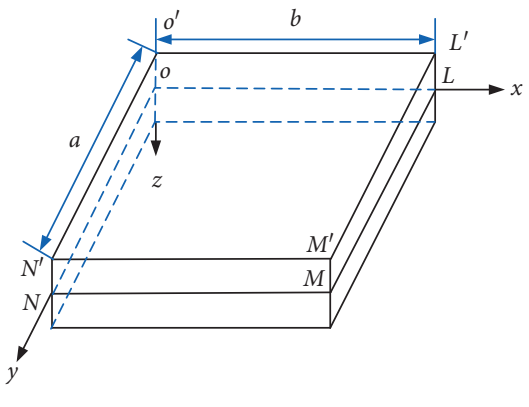

(b)

FIgURE 5: Mechanical model with fixed support on three sides and simple support on one side.

Poisson's ratio of roof rock, span $(\mathrm{m})$ of the stope roof, and normal stress $(\mathrm{MPa})$ acting vertically on $y$-axis plane, respectively; $\tau_{x y}$ denotes the shear stress $(\mathrm{MPa})$ acting on the $x y$ plane, which is positive consistent with the negative direction of the $y$-axis; $x, y$, and $z$ are the distances $(\mathrm{m})$ on the coordinate axis. By analyzing the mechanical model, it is obtained that the stress distributions at the midpoints of $O^{\prime} L^{\prime}$ and $N^{\prime} M^{\prime}$ edges and midpoint of $O^{\prime} N^{\prime}$ edge in Figure 5(b) are expressed in formulas (2) and (3).

$$
\begin{aligned}
& \left\{\begin{array}{l}
\sigma_{x}=\frac{\pi^{2} E \mu \mathrm{Ah}}{2 a^{2}\left(1-\mu^{2}\right)} \\
\sigma_{y}=\frac{\pi^{2} \mathrm{EAh}}{2 a^{2}\left(1-\mu^{2}\right)}, \\
\tau_{x y}=0, \\
\sigma_{x}=\frac{2 \mathrm{EAh}}{b^{2}\left(1-\mu^{2}\right)} \\
\sigma_{y}=\frac{2 \mathrm{EAh} \mu}{b^{2}\left(1-\mu^{2}\right)} \\
\tau_{x y}=0 .
\end{array}\right.
\end{aligned}
$$

By comparing formulas (2) and (3), the stress at the midpoints of $O^{\prime} L^{\prime}$ and $N^{\prime} M^{\prime}$ edges is larger than that at the midpoint of $O^{\prime} N^{\prime}$ edge. Due to use of gangue backfilling technology, backfilling while mining of the goaf allows the roof rock of the stope to not completely cave. Instead, with the constant advance of the working face, due to compressive deformation of the backfilling body under gravity of overlying strata, the roof is suspended and the immediate roof caves. Moreover, the main roof bends and deforms with the compressive deformation of the backfilling body. When the overhanging roof reaches its limit, it bends near the midpoints of $O L$ and $N M$ edges first.

4.2. Determination of the Key Strata of the Fully Mechanized Coal Mining Face Backfilled with Gangue. Academician Qian Minggao proposed the key stratum theory in the previous study [50]. When there are multilayer strata in overlying strata of the stope, the strata that control all or part of activities of rock mass are called the key strata [50]. The key strata are mainly determined based on deformation and breaking characteristics. When the key strata are broken, the subsidence and deformation of all or local strata above the key strata are coordinated and consistent with each other. The former is known as main key strata, while the latter is called inferior key strata; that is, the fracture of the key strata will lead to the overall movement of all or considerable part of overlying strata. In general, the key strata are the main bearing layers, which bear part of the weight of overlying strata in the form of slabs or simplified beam structures before breaking and form structures of voussoir beams after breaking. Its structural morphology reflects the strata 
movement form. According to definition and deformation characteristics of the key strata, if $n$ layers are deformed synchronously and coordinately, the lowest strata are the key strata. The physical and mechanical parameters of overlying strata of the 12031 working face in Jiulishan Coal Mine are listed in Table 2.

According to formula (4), the loading action of the $n$th stratum on the $m$ th stratum is calculated from the lower stratum $(n>m)$.

$$
q_{m \mid n}=\frac{E_{m} h_{m}^{3} \sum_{i=1}^{n} \gamma_{i} h_{i}}{\sum_{i=1}^{n} E_{i} h_{i}^{3}} .
$$

If meeting $q_{m \mid n+1}<q_{m \mid n}$, then the $n+1$ stratum is regarded as a hard stratum; otherwise, load of the $n+2$ th stratum on the $n$th stratum is continuously calculated. By substituting data in Table 2 into formula (4), load of overlying strata in each layer on A7 and A11 strata is obtained. Based on the calculation results and determination criteria, it is comprehensively considered that there are two hard strata, namely, A7 and A11, in the overlying strata above the 12031 working face of Jiulishan Coal Mine. The criteria for determining the key strata should satisfy not only the stiffness condition, but also the strength condition, which is generally expressed by the interval of roofing breaking $L_{k}$ of strata as follows:

$$
L_{k}=h_{k} \sqrt{\frac{2 \sigma_{t k}}{q_{k}}},
$$

where $h_{k}, \sigma_{t k}$, and $q_{k}$ indicate the thickness (m), tensile strength $(\mathrm{MPa})$, and load $(\mathrm{kN})$ borne by the $k$ th hard stratum, respectively.

It is assumed that the $n$th and $m$ th strata are hard $(n>m)$. If $L_{n}>L_{m>L}$, the $n$th stratum is the main key stratum, while the $m$ th and first strata are the inferior key strata. If $L_{n}>L_{m>L}$, then load on the $n$th hard stratum should be added onto the $m$ th stratum to recalculate the interval of roofing breaking of the $m$ th stratum. After that, by comparing with the first stratum, the stratum with the longest interval of roofing breaking is the main key stratum, followed by the inferior key stratum, while the $n$th stratum is not key stratum. According to the criteria for determining the key strata and the physical and mechanical parameters of overlying strata above the 12031 working face of Jiulishan Coal Mine, the key stratum in the coal seam is determined as A7, while the inferior key stratum is A11.

\subsection{Analysis on Bending Deformation of the Main Roof of the} Fully Mechanized Coal Mining Face Backfilled with Gangue. The analysis on the position of deformation of the main roof of the fully mechanized coal mining face backfilled with gangue based on thin-plate theory shows that the main roof firstly bends at the middle position. In accordance with the assumption of Winkler foundation [15], the main roof is assumed as an elastic beam on the foundation. Therefore, the mechanical model was established only based on the part from the main roof to the coal seam. Owing to the main key strata of the fully mechanized coal mining face backfilled with gangue bend, rather than break [46], the uniformly distributed load $q_{0}$ of overlying strata above the main roof is only calculated from the lower part of the main key strata to the inferior key strata. Because the mechanical model is symmetrical, a half of the model was taken for mechanical analysis, and the unit length was taken in $z$ direction. The starting point on the left end of the beam is the coal wall of the working face, and the length $l$ of the beam is a half of the length of the backfilling zone. The bearing body in the lower part of the main roof is backfilling body and the elastic modulus is constantly changing in the process of continuous compression of the backfilling body, so the supporting force of the bearing body to the key strata is set as $p(x)$. The mechanical model and stress model of the main roof of the fully mechanized coal mining face backfilled with gangue are shown in Figure 6.

By using the mechanical model of the main roof of the fully mechanized coal mining face backfilled with gangue in Figure 6, the main roof and the backfilling body below as the bearing body were analyzed and studied based on a beam model on Winkler elastic foundation. In accordance with the assumption of Winkler foundation [4, 31, 32], the substance at any point on the surface of the foundation is directly proportional to the pressure $p$ on the unit area of the point, expressed as follows:

$$
p=k \omega
$$

where $\omega$ and $k$ separately represent the subsidence of the foundation and foundation coefficient. The bearing body in the mechanical model of the main roof belongs to the backfilling body that is the elastic foundation. Under the load $q_{0}$ of overlying strata, the displacement between the beam (main roof) and the foundation (backfilling body) is defined as $x$, while the pressure between them is defined as $p$ $(x)$. By analyzing the beam, the relationship among $q_{0}, p(x)$, and deflection $\omega$ of the beam is expressed as follows:

$$
q_{o}-p(x)=\mathrm{EI} \frac{\mathrm{d}^{4} \omega(x)}{\mathrm{d} x^{4}},
$$

where EI denotes the stiffness of the beam section. $\beta$ is taken as the characteristic coefficient, expressed as follows:

$$
\beta=\sqrt[4]{\frac{k}{4 \mathrm{EI}}}
$$

Formula (7) can be rewritten as follows:

$$
\frac{q_{o}}{\mathrm{EI}}=\frac{\mathrm{d}^{4} \omega(x)}{\mathrm{d} x^{4}}+4 \beta \omega .
$$

By solving formula (9), the general solution to formulas is attained as follows:

$$
\begin{gathered}
\omega(x)=e^{\beta x}(A \cos \beta x+B \sin \beta x)+e^{-\beta x} \\
\cdot(C \cos \beta x+D \sin \beta x)+\frac{q_{o}}{k} .
\end{gathered}
$$

Because the established mechanical model of the main roof is a finite-length beam, the formula for the deflection of the beam without load is obtained by solving formula (10) 
TABLe 2: Physical and mechanical parameters of overlying strata.

\begin{tabular}{|c|c|c|c|c|c|c|}
\hline No. & Lithology & $\begin{array}{l}\text { Thickness } \\
\text { (m) }\end{array}$ & $\begin{array}{c}\text { Elastic modulus } \\
(\mathrm{GPa})\end{array}$ & $\begin{array}{c}\text { Compressive strength } \\
(\mathrm{MPa})\end{array}$ & $\begin{array}{l}\text { Tensile strength } \\
(\mathrm{MPa})\end{array}$ & $\begin{array}{l}\text { Volume force } \\
\left(\mathrm{kN} \cdot \mathrm{m}^{-3}\right)\end{array}$ \\
\hline 1 & Loess layer & 23.56 & 0 & - & - & 18 \\
\hline 2 & Laterite layer & 36.80 & 0 & - & - & 18 \\
\hline 3 & $\begin{array}{c}\text { Laterite } \\
\text { conglomerate }\end{array}$ & 30.62 & 1.56 & 10.21 & - & 21 \\
\hline 4 & Siltstone & 14.00 & 1.65 & 15.96 & 1.65 & 25 \\
\hline 5 & Sandstone & 5.37 & 1.94 & 21.23 & 1.82 & 26 \\
\hline 6 & Siltstone & 8.90 & 11.23 & 40.5 & 3.72 & 27 \\
\hline 7 & Sandstone & 20.60 & 18.14 & 80.5 & 7.1 & 27 \\
\hline 8 & Mudstone & 1.60 & 14.22 & 56.8 & 4.3 & 27 \\
\hline 9 & Sandstone & 13.46 & 13.2 & 50.3 & 3.91 & 27 \\
\hline 10 & Siltstone & 6.05 & 12.2 & 43.21 & 3.92 & 27 \\
\hline 11 & Sandstone & 15.48 & 16.2 & 69.8 & 5.97 & 27 \\
\hline 12 & Mudstone & 1.10 & 9.58 & 38.9 & 3.25 & 27 \\
\hline 13 & No. $\mathrm{II}_{1}$ coal seam & 5.5 & 1.93 & 13.9 & 0.73 & 15 \\
\hline 14 & Siltstone & 11.71 & 9.26 & 37.5 & 3.16 & 27 \\
\hline 15 & Limestone & 0.55 & 6.72 & 28.91 & 2.36 & 26 \\
\hline
\end{tabular}

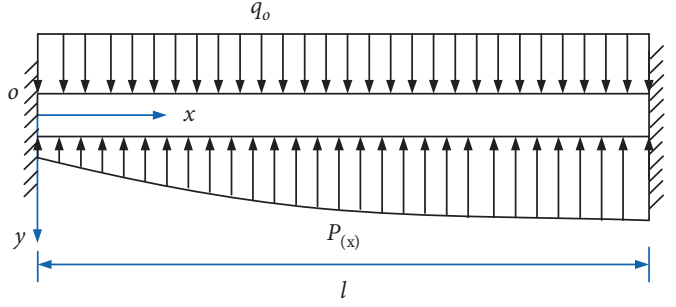

(a)

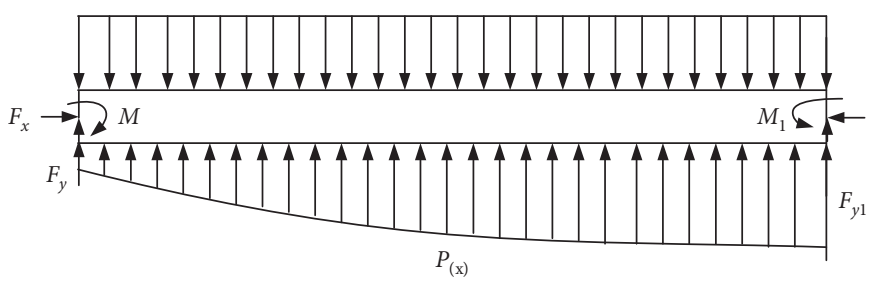

(b)

FIGURE 6: Mechanical model and stress model of the main roof. (a) Mechanical model of the main roof. (b) Stress analysis of the main roof.

with the initial parameter method in the existing studies $[36,51]$.

$$
\omega(x)=\omega_{o} \cdot \varphi_{1}+\theta_{o} \frac{\varphi_{2}}{\beta}-M_{o} \frac{\varphi_{3}}{\operatorname{EI} \beta^{2}}-Q_{O} \frac{\varphi_{4}}{\operatorname{EI} \beta^{3}},
$$

where $M_{\mathrm{o}}, \theta_{\mathrm{o}}, Q_{\mathrm{o}}$, and $\omega_{\mathrm{o}}$ represent the bending moment, rotation angle, shear force, and deflection at the breaking point $(x=0)$ of the finite-length beam, respectively; $\Phi_{1}, \Phi_{2}$, $\Phi_{3}$, and $\Phi_{4}$ are all Krylov functions of $\beta x$.

$$
\left\{\begin{array}{l}
\varphi_{1}(\beta x)=\operatorname{ch} \beta x \cos \beta x, \\
\varphi_{2}(\beta x)=\frac{1}{2}(\operatorname{ch} \beta x \sin \beta x+\operatorname{sh} \beta x \cos \beta x), \\
\varphi_{3}(\beta x)=\frac{1}{2} \operatorname{sh} \beta x \sin \beta x \\
\varphi_{4}(\beta x)=\frac{1}{4}(\operatorname{ch} \beta x \sin \beta x+\operatorname{sh} \beta x \cos \beta x) .
\end{array}\right.
$$

For the uniformly distributed load $q_{0}$ borne by the beam on the foundation, formula (13) is used as the correction term of the deflection.

$$
\omega(x)_{q_{o}}=\int_{0}^{x} q_{o} \theta_{4}[\beta(x-\xi)] \mathrm{d} \xi=q_{o} \frac{1-\varphi_{1}}{k} .
$$

After using the correction term of formula (13), when the finite-length elastic beam on the foundation bears local load, the deflection is expressed as follows:

$$
\omega(x)=\omega_{o} \cdot \varphi_{1}+\theta_{o} \frac{\varphi_{2}}{\beta}-M_{o} \frac{\varphi_{3}}{\mathrm{EI} \beta^{2}}+Q_{O} \frac{\varphi_{4}}{\operatorname{EI} \beta^{3}}+q_{o} \frac{1-\varphi_{1}}{k} .
$$

By substituting boundary conditions of the beam into formula (14), the deflection $\omega(x)$, rotation angle $\theta(x)$, bending moment $M(x)$, and shear force $Q(x)$ are expressed as follows:

$$
\begin{gathered}
\omega(x)=-M_{o} \frac{\varphi_{3}}{\mathrm{EI} \beta^{2}}+Q_{O} \frac{\varphi_{4}}{\mathrm{EI} \beta^{3}}+q_{o} \frac{1-\varphi_{1}}{k}, \\
\theta(x)=\frac{\mathrm{d} \omega(x)}{\mathrm{d} x}=-M_{o} \frac{\varphi_{2}}{\mathrm{EI} \beta}+Q_{O} \frac{\varphi_{3}}{\mathrm{EI} \beta^{2}}+4 q_{o} \frac{\varphi_{4} \beta}{k}, \\
M(x)=-\mathrm{EI} \frac{\mathrm{d}^{2} \omega(x)}{\mathrm{d} x^{2}}=M_{o} \varphi_{1}+Q_{O} \frac{\varphi_{2}}{\beta}+4 q_{o} \frac{\mathrm{EI} \beta^{2} \varphi_{3}}{k},
\end{gathered}
$$




$$
Q(x)=-\mathrm{EI} \frac{\mathrm{d} \omega^{3}(x)}{\mathrm{d} x^{3}}=-4 M_{o} \beta \varphi_{4}+Q_{O} \varphi_{1}+4 \mathrm{EI} \beta^{3} q_{o} \frac{\varphi_{2}}{k} .
$$

By substituting boundary conditions of the beam into formulas (16) and (18), binary linear equations of $M_{0}$ and $Q_{0}$ are obtained.

$$
\left\{\begin{array}{l}
-M_{o} \frac{\varphi_{2}}{\mathrm{EI} \beta}-Q_{O} \frac{\varphi_{3}}{\mathrm{EI} \beta^{2}}+4 q_{o} \frac{\varphi_{4} \beta}{k}=0, \\
-4 M_{o} \beta \varphi_{4}-Q_{O} \varphi_{1}+4 \mathrm{EI} \beta^{3} q_{o} \frac{\varphi_{2}}{k}=0 .
\end{array}\right.
$$

Parameters $M_{0}$ and $Q_{0}$ are obtained by solving the above binary linear equations.

$$
\left\{\begin{array}{l}
M_{o}=\frac{2 \mathrm{EI} \beta^{2} q_{0}}{k} \cdot \frac{\operatorname{sh}(2 l \beta)-\sin (2 l \beta)}{\operatorname{sh}(2 l \beta)+\sin (2 l \beta)}, \\
Q_{O}=\frac{4 \mathrm{EI} \beta^{3} q_{o}}{k} \cdot \frac{\operatorname{ch}(2 l \beta)-\cos (2 l \beta)}{\operatorname{sh}(2 l \beta)+\sin (2 l \beta)} .
\end{array}\right.
$$

By substituting formula (20) into the formula for boundary conditions of the beam, the formula for deflection of the finite-length elastic beam on the foundation when bearing the uniformly distributed load is obtained.

$$
\begin{aligned}
\omega(x)= & \frac{2 q_{0} \varphi_{3}}{k} \cdot \frac{\operatorname{sh}(2 l \beta)-\sin (2 l \beta)}{\operatorname{sh}(2 l \beta)+\sin (2 l \beta)_{3}} \\
& +\frac{q_{0} \varphi_{4}}{k} \cdot \frac{\operatorname{ch}(2 l \beta)-\cos (2 l \beta)}{\operatorname{sh}(2 l \beta)+\sin (2 l \beta)}+q_{o} \frac{1-\varphi_{1}}{k}, \\
M(x)= & \frac{2 \mathrm{EI} \beta^{2} q_{0} \varphi_{1}}{k} \frac{\operatorname{sh}(2 l \beta)-\sin (2 l \beta)}{\operatorname{sh}(2 l \beta)+\sin (2 l \beta)} \\
& +\frac{4 \mathrm{EI} \beta^{2} q_{0} \varphi_{2}}{k} \frac{\operatorname{ch}(2 l \beta)-\cos (2 l \beta)}{\operatorname{sh}(2 l \beta)+\sin (2 l \beta)}+4 q_{o} \frac{\operatorname{EI} \beta^{2} \varphi_{3}}{k} .
\end{aligned}
$$

According to determination based on thin-plate theory and deformation characteristics of the beam under stress, the points of the maximum deflection and bending moment of the beam appear at $x=l$, thus obtaining the maximum deflection of the beam.

$$
\begin{aligned}
\omega(l)= & \frac{2 q_{0} \varphi_{3}(l \beta)}{k} \cdot \frac{\operatorname{sh}(2 l \beta)-\sin (2 l \beta)}{\operatorname{sh}(2 l \beta)+\sin (2 l \beta)_{3}}+\frac{q_{0} \varphi_{4}(l \beta)}{k} \\
& \cdot \frac{\operatorname{ch}(2 l \beta)-\cos (2 l \beta)}{\operatorname{sh}(2 l \beta)+\sin (2 l \beta)}+q_{o} \frac{1-\varphi_{1}(l \beta)}{k}, \\
M(l)= & \frac{2 \operatorname{EI} \beta^{2} q_{0} \varphi_{1}(l \beta)}{k} \frac{\operatorname{sh}(2 l \beta)-\sin (2 l \beta)}{\operatorname{sh}(2 l \beta)+\sin (2 l \beta)}+\frac{4 \operatorname{EI}^{2} q_{0} \varphi_{2}(l \beta)}{k} \\
& \cdot \frac{\operatorname{ch}(2 l \beta)-\cos (2 l \beta)}{\operatorname{sh}(2 l \beta)+\sin (2 l \beta)}+4 q_{o} \frac{\operatorname{EI}^{2} \varphi_{3}(l \beta)}{k} .
\end{aligned}
$$

In accordance with strength theory of the beam, $\sigma_{\max }$, $M_{\max }$, and $W$ are separately shown in the following formulas:

$$
\begin{aligned}
\sigma_{\max } & =\frac{M_{\max }}{W}=\frac{1}{10} \sigma_{C}, \\
M_{\max } & =M(l), \\
W & =\frac{1}{6} h^{2},
\end{aligned}
$$

where $M_{\max }, W, \sigma_{\mathfrak{c}}$, and $h$ denote the maximum bending moment, bending modulus of section, bending modulus of section, and height of the beam, respectively.

By substituting formulas (24), (25), and (26) into formula (27), the relationship between the compressive strength and the maximum bending moment is shown as follows:

$$
\begin{aligned}
& \frac{2 \mathrm{EI} \beta^{2} q_{0} \varphi_{1}(l \beta)}{k} \frac{\operatorname{sh}(2 l \beta)-\sin (2 l \beta)}{\operatorname{sh}(2 l \beta)+\sin (2 l \beta)}+\frac{4 \mathrm{EI}^{2} q_{0} \varphi_{2}(l \beta)}{k} \\
& \cdot \frac{\operatorname{ch}(2 l \beta)-\cos (2 l \beta)}{\operatorname{sh}(2 l \beta)+\sin (2 l \beta)} \\
& +4 q_{o} \frac{\mathrm{EI} \beta^{2} \varphi_{3}(l \beta)}{k}=\frac{\sigma_{\mathrm{c}} h^{2}}{60} .
\end{aligned}
$$

According to the existing study [43], the maximum deflection of the main roof is shown in the following formula:

$$
\omega(x)_{\max }=\frac{\left(\gamma h_{1}+q_{0}\right) \cdot L_{1}^{4}}{384 E_{1} I} .
$$

Therefore, when meeting the conditions of formula (29), the main roof is broken.

$$
\omega(l) \geq \omega(x)_{\max } .
$$

In the calculation results based on Winkler theory, the bending deformation of the main roof is calculated through the numerical calculation. Based on the actual conditions of Jiulishan Coal Mine, the results of bending deformation of the main roof are obtained through calculation according to parameters of strata above the working face and the test for determining parameters of bulking characteristics of backfilled gangue. Before the calculation, it is necessary to introduce the elastic foundation coefficient of strata [46]. According to the existing study [46], the bearing body below the main roof includes crushed rock blocks of the immediate roof and backfilling body, which belong to the elastic foundation. The $\mathrm{C} 1$ and $\mathrm{C} 2$ strata between the goaf and the immediate roof are taken as the cushion, as shown in Figure 7. The calculation results of the elastic foundation coefficient of strata in the existing research [46] are demonstrated as follows:

$$
k=\frac{1}{\sum_{i=1}^{2} h_{i} / E_{i}} .
$$


$q_{0}$

Inferior key strata (main roof)
Gangue backfilling body

FIGURE 7: Schematic diagram of strata structure.

As $q_{\mathrm{o}}=\gamma H=22 \mathrm{~m} \times 27 \mathrm{kN} / \mathrm{m}^{3}=0.594 \mathrm{MPa}, E=16.2 \mathrm{GPa}$, $E_{1}=9.58 \mathrm{GPa}, E_{2}=10 \mathrm{GPa}, h=15.48 \mathrm{~m}, h_{1}=1.1 \mathrm{~m}, h_{2}=3.0 \mathrm{~m}$, and $\sigma_{\mathrm{c}}=69.8 \mathrm{MPa}$, the cross-sectional moments of inertia $I, k$, and $\beta$ of the main roof are displayed as follows:

$$
\begin{aligned}
& I=\frac{1}{12} h^{3}=309.12 \mathrm{~m}^{3}, \\
& k=\frac{1}{\sum_{i=1}^{2} h_{i} / E_{i}}=2,410,669 \mathrm{KN} / \mathrm{m}^{3}, \\
& \beta=\sqrt[4]{\frac{k}{4 \mathrm{EI}}}=0.105 \mathrm{~m}^{-1} .
\end{aligned}
$$

Given $h=15.48 \mathrm{~m}$ and $\sigma_{\mathrm{c}}=69.8 \mathrm{MPa}$, then $l=22.66 \mathrm{~m}$ can be obtained by solving formula (28).

When $l=22.66 \mathrm{~m}$, the maximum deflection $w(l)=1.38 \mathrm{~mm}$ of the main roof can be obtained by solving formula (23).

It is known that $\gamma=27 \mathrm{KN} / \mathrm{m}^{3}$. By substituting the measured data of the mine, namely, $L_{1}=58 \mathrm{~m}$ into formula (29), the following result is obtained:

$$
\omega(x)_{\max }=\frac{\left(\gamma h+q_{0}\right) \cdot L^{4}}{384 \mathrm{EI}}=5.56 \mathrm{~mm}
$$

Therefore, $\omega(l)<\omega(x)_{\max }$, according to which it can be determined that the main roof does not break, but it bends and sinks with the constant compaction of the backfilling body during stopping of the working face in the test of mining Jiulishan Coal Mine with gangue backfilling.

\section{Movement Laws of Overlying Strata during Gangue Backfilling Mining}

\subsection{Calculation Model and Parameters}

5.1.1. Boundary Conditions of the Model. Based on the numerical simulation, strata movement laws were studied. Due to the limitation of the number of run units of the simulation software, the simplified method is usually adopted; that is, the strata not simulated are regarded as the uniformly distributed load that is applied on the upper boundary of the model. According to different research purposes, the boundaries of the model are correspondingly adjusted. Through the numerical simulation, this study mainly investigated changes of the main roof and key strata and surface deformation laws, and the vertical range of the model was from the floor of the coal seam to the surface $[52,53]$.
A strain-hardening model was used for calculation. With strike $\times$ tendency $\times$ height $=400 \mathrm{~m} \times 150 \mathrm{~m} \times 225 \mathrm{~m}$, a plane strain model was utilized. The displacement boundary conditions of the model are shown as follows: the left and right boundaries and the lower boundary of the model are used as displacement boundaries. The displacements of the left and right boundaries in $x$ direction and the displacement of the lower boundary in $y$ direction are limited. The model is demonstrated in Figure 8.

5.1.2. Division of Elements of the Numerical Model and Determination of Calculation Parameters. The left, right, front, and back sides of the model are single-constraint boundaries and the horizontal constraint is applied; that is, the horizontal displacement of the boundary is zero while boundary nodes are only allowed to move along the vertical direction. The bottom of the model is a fully constrained boundary; that is, the horizontal and vertical displacements of the boundary nodes in the bottom are both zero. According to the buried depth of the model and Heim's hypothesis, the gravity stress of the original rock acts on the upper boundary. The calculation model based on FLAC ${ }^{3 \mathrm{D}}$ software is displayed in Figure 9.

The physical and mechanical parameters of coal seams and overlying strata above the mining face backfilled with gangue and mechanical parameters of the coal-rock contact surface are listed in Table 2 . The gangue backfilling materials mostly are siltstone from the floor and mudstone from the roof, and some are sandstone from the roof. The mechanical parameters of backfilled gangue are shown in Table 3.

5.1.3. Simulation Schemes. The elastic modulus of gangue backfilling materials is one of key factors for gangue backfilling mining. For the nonlinear elastic rock, the stressstrain relationship can be expressed by a single valued function $\sigma=f(\varepsilon)$. Because $\sigma-\varepsilon$ shows a curvilinear relationship, the elastic modulus, as a variable, at any point $P$ on the curve depends on the position of the point [4]. Because the gangue backfilling body is constantly compacted under gravity of overlying strata, the elastic modulus thereof changes continuously. When the backfilling body is completely compacted, it can be considered that the elastic modulus thereof reaches the maximum. To study movement laws of the main roof and key strata before and after complete compaction of the gangue backfilling body, the backfilling body is compacted by changing the elastic modulus of the backfilling body at different stages in the numerical simulation. It is supposed that the initial elastic modulus of the backfilling body is $1 \mathrm{GPa}$. When the elastic modulus of the backfilling body at different stages increases to $5,10,15$, and $20 \mathrm{GPa}$ with the constant compaction of the backfilling body, the movement characteristics of strata before and after complete compaction were studied by changing the elastic modulus. In addition, five numerical simulation schemes under the elastic modulus of the backfilling body of $1,5,10,15$, and $20 \mathrm{GPa}$ were implemented. Based on the above five schemes, the bending and subsidence of the main roof of the working face, compressive 


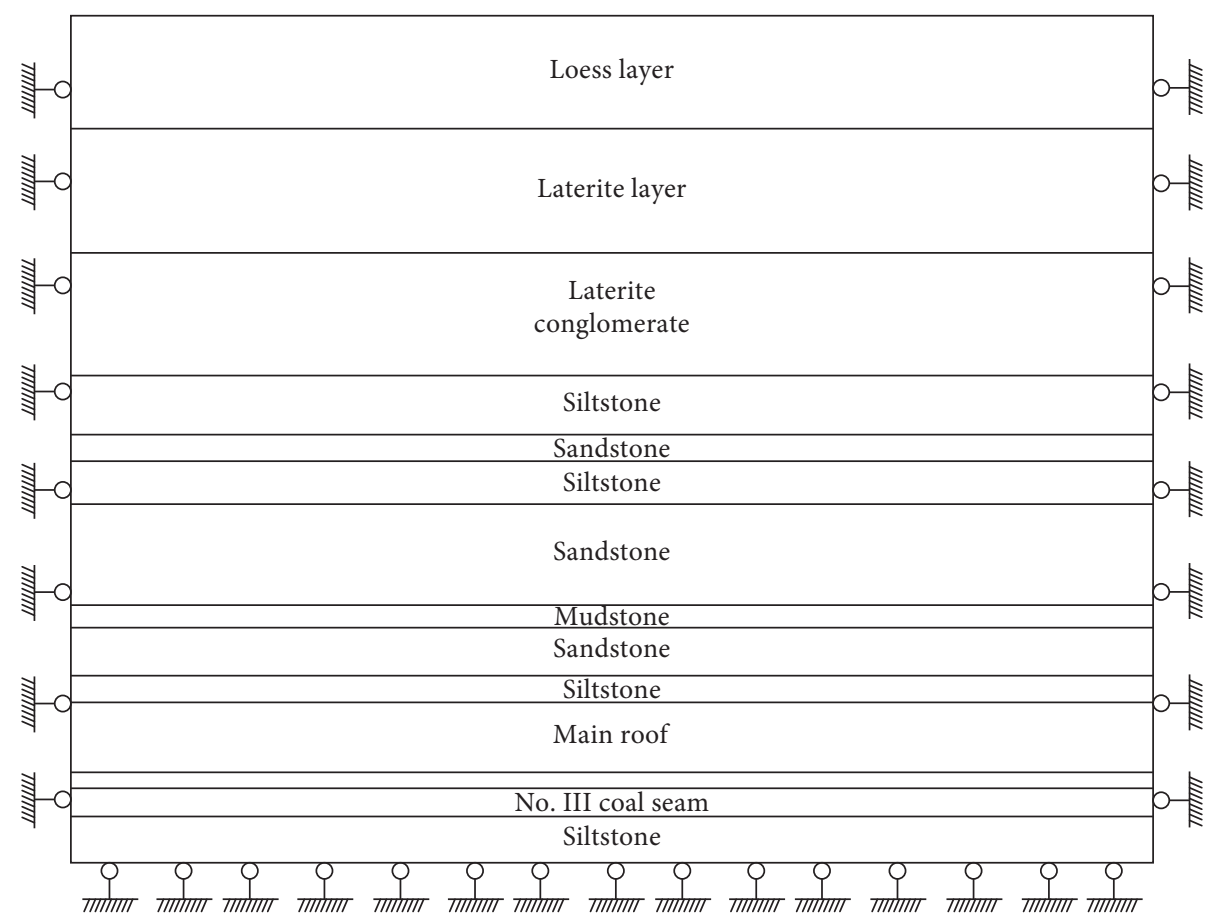

FIGURE 8: Original model.

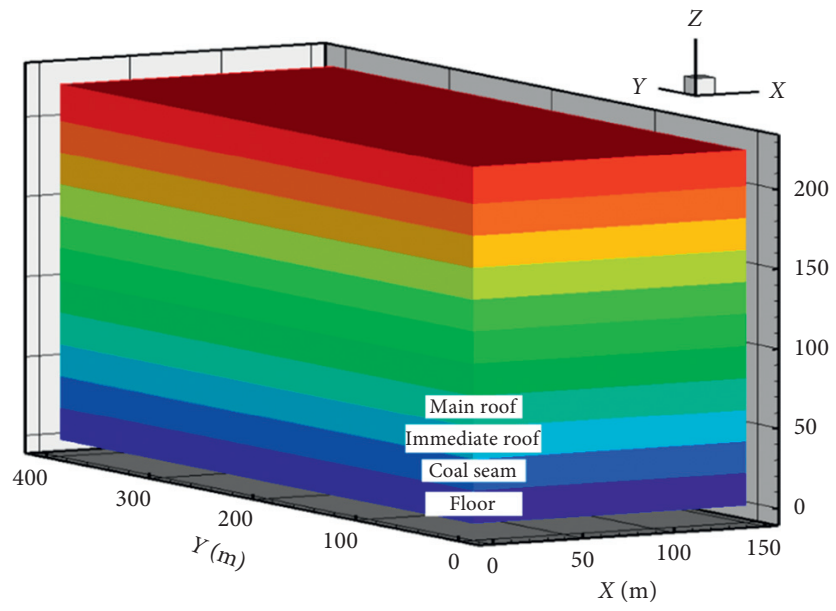

FIGURE 9: Grid model of numerical calculation based on FLAC ${ }^{3 \mathrm{D}}$ software.

TABLE 3: Physical and mechanical parameters of backfilled gangue.

\begin{tabular}{lcccc}
\hline Backfilling material & Elastic modulus $(\mathrm{GPa})$ & Compressive strength $(\mathrm{MPa})$ & Tensile strength $(\mathrm{MPa})$ & Volume force $\left(\mathrm{kN} \cdot \mathrm{m}^{-3}\right)$ \\
\hline Sandstone & 16.2 & 69.8 & 5.97 & 27 \\
Mudstone & 9.58 & 38.9 & 3.25 & 27 \\
Siltstone & 9.26 & 37.5 & 3.16 & 27 \\
\hline
\end{tabular}

deformation of the backfilling body, surface deformation laws and floor failure were analyzed.

5.2. Movement Laws of Overlying Strata under Different Elastic Moduli of Backfilled Gangue. Through the simulation on the compressive deformation of the backfilling body, the compressive deformation laws of the backfilling body were analyzed under the elastic modulus of 1, 5, 10, 15, and $20 \mathrm{GPa}$. The simulated 12031 backfilling mining face in Jiulishan Coal Mine advances for $100 \mathrm{~m}$ along the strike direction in total. In this case, the deformation of the backfilling body and distributions of displacement vector of the backfilling body and vertical stress were obtained. 
(1) Using gangue with the elastic modulus of $1 \mathrm{GPa}$ as backfilling materials for simulation: when gangue with the elastic modulus of $1 \mathrm{GPa}$ is used for backfilling, movement of overlying strata and distributions of displacement vector of surrounding rock and vertical stress when the working face advances for $100 \mathrm{~m}$ are obtained in Figure 10.

As displayed in Figure 10, overlying strata during gangue backfilling mining move more gently compared with those during the fully caving mining. By using this method, strata movement is well controlled and the main roof does not break, but it bends. Because the roof is effectively controlled, the abutment stress of the coal wall and roof subsidence are small. Due to influence of the advanced stress, the coal wall slightly deforms. Because of the small elastic modulus and low strength of backfilled gangue, the backfilling body exhibits great compressive deformation, but the failure depth of the floor is small. The above distribution of vertical stress suggests that the maximum abutment stress in front of the coal wall is $25 \mathrm{MPa}$.

(2) Taking gangue with the elastic modulus of $5 \mathrm{GPa}$ as backfilling materials for simulation: when gangue with the elastic modulus of $5 \mathrm{GPa}$ is utilized for backfilling, the movement of overlying strata and distributions of displacement vector of surrounding rock and vertical stress when the working face advances for $100 \mathrm{~m}$ are demonstrated in Figure 11.

As illustrated in Figure 11, overlying strata during gangue backfilling mining move more gently compared with those during the fully caving mining. Strata movement is well controlled and the main roof bends instead of breaking. Because the roof is effectively controlled, the abutment stress of the coal wall and roof subsidence are small. Because of influence of the advanced stress, the coal wall deforms slightly. Since the elastic modulus of backfilled gangue relatively rises and the strength increases accordingly, the compressive deformation of the backfilling body relatively reduces and the failure depth of the floor is still small. The above distribution of vertical stress demonstrates that the maximum abutment stress in front of the coal wall is $21 \mathrm{MPa}$.

(3) Utilizing gangue with the elastic modulus of $10 \mathrm{GPa}$ as backfilling materials for simulation, when taking gangue with the elastic modulus of $10 \mathrm{GPa}$ for backfilling, the movement of overlying strata and distributions of displacement vector of surrounding rock and vertical stress with the working face advancing for $100 \mathrm{~m}$ are illustrated in Figure 12.

As shown in Figure 12, compared with the movement of overlying strata during mining with the fully caving method, the strata movement during gangue backfilling mining is gentler. In this way, strata movement is well controlled and the main roof does not break but bends. Due to effective control on the roof, the abutment stress of the coal wall and roof subsidence are small. Affected by the advanced stress, the coal wall slightly deforms. Due to the constant increase of the elastic modulus and corresponding rise of strength of backfilled gangue, the compressive deformation of the backfilling body decreases correspondingly and the failure depth of the floor is still small. As shown in the above distribution of vertical stress, the maximum abutment stress in front of the coal wall is $20 \mathrm{MPa}$.

(4) Using gangue with the elastic modulus of $15 \mathrm{GPa}$ as backfilling materials for simulation: when gangue with the elastic modulus of $15 \mathrm{GPa}$ is utilized as backfilling materials, the movement of overlying strata and distributions of displacement vector of surrounding rock and vertical stress are obtained as the working face advances for $20,40,60,80$, and $100 \mathrm{~m}$, as displayed in Figure 13.

As shown in Figure 13, overlying strata during gangue backfilling mining move more gently in comparison with that in mining with the fully caving method. Strata movement is well controlled and the main roof does not break, but it bends. Attributed to the effective control on the roof, the abutment stress of the coal wall and roof subsidence are small. Influenced by the advanced stress, the coal wall slightly deforms. When the elastic modulus of backfilled gangue rises to $15 \mathrm{GPa}$, the compressive deformation of the backfilling body is small, which changes little compared with the case under the elastic modulus of backfilled gangue of $10 \mathrm{GPa}$, and the floor is still found to have a small failure depth. The above distribution of vertical stress illustrates that the maximum abutment stress in front of the coal wall is $19 \mathrm{MPa}$.

(5) Utilizing gangue with the elastic modulus of $20 \mathrm{GPa}$ as backfilling materials for simulation. When gangue with the elastic modulus of $20 \mathrm{GPa}$ is used as the backfilling materials, the movement of overlying strata and distributions of displacement vector of surrounding rock and vertical stress are obtained in Figure 14 as the working face advances for $100 \mathrm{~m}$.

As displayed in Figure 14, the movement of overlying strata during gangue backfilling mining is gentler in comparison with that in mining with the fully caving method. The strata movement is well controlled and the main roof bends rather than breaks. Under the effective control of the roof, the abutment stress of the coal wall and roof subsidence are small. When the elastic modulus of backfilled gangue increases to $20 \mathrm{GPa}$, the compressive deformation of the backfilling body is small, which shows a small change compared with that when the elastic modulus is $15 \mathrm{GPa}$, and the failure depth of the floor is still small. The above distribution of vertical stress shows that the maximum abutment stress in front of the coal wall is $19 \mathrm{MPa}$. Compared 


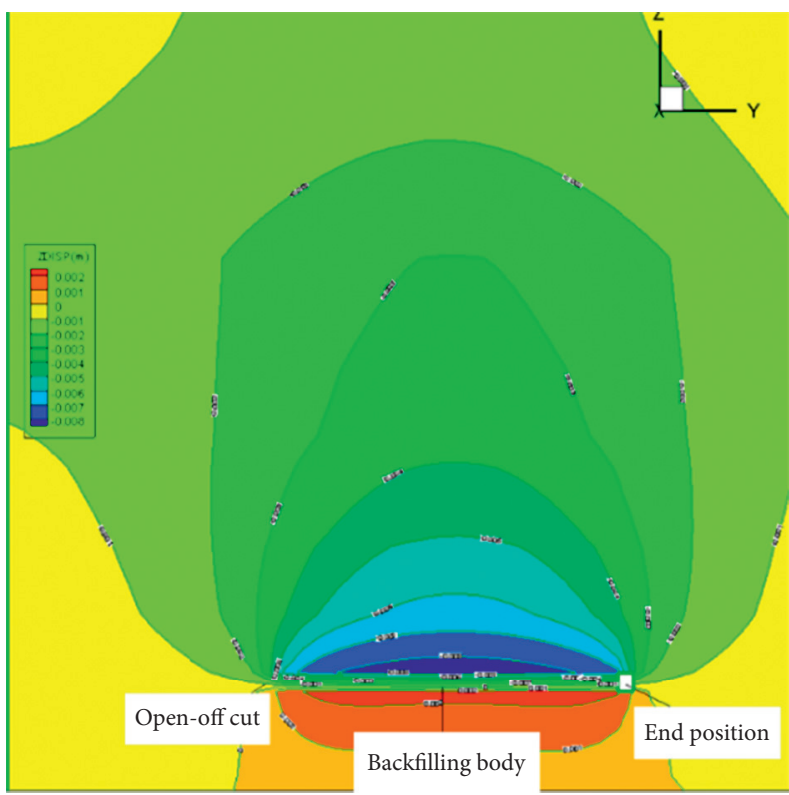

(a)

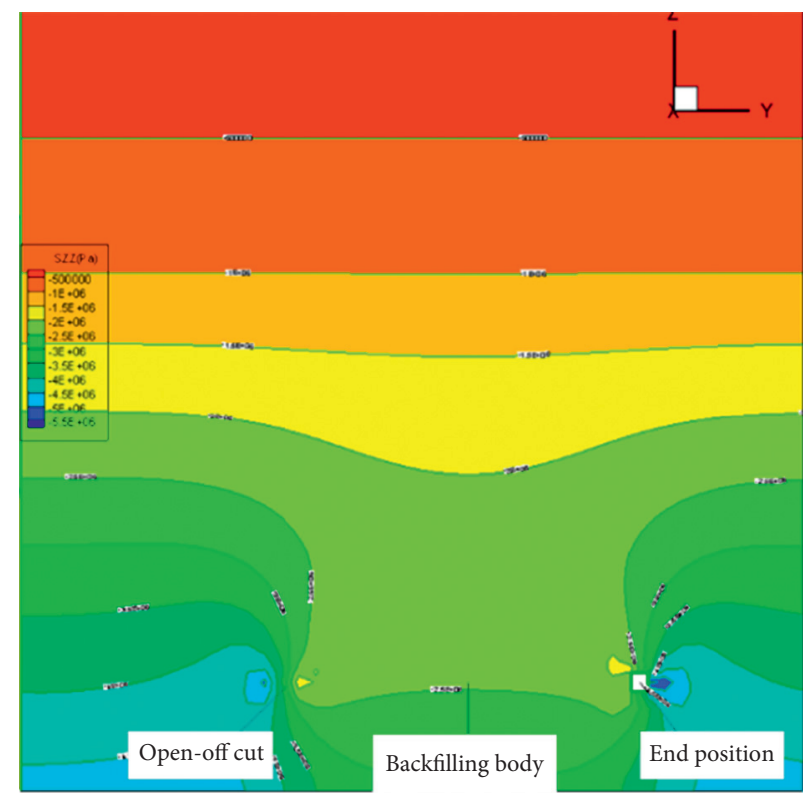

(b)

FIGURE 10: Movement of overlying strata when the working face advances for $100 \mathrm{~m}$ under the elastic modulus of gangue of $1 \mathrm{GPa}$. (a) Displacement vector of surrounding rock. (b) Distribution of vertical stress.

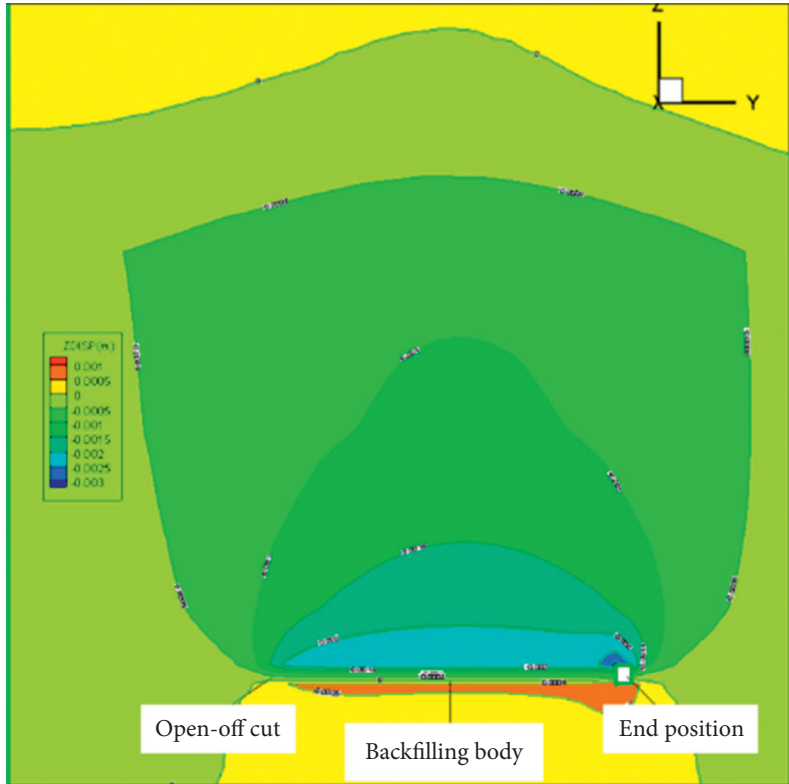

(a)

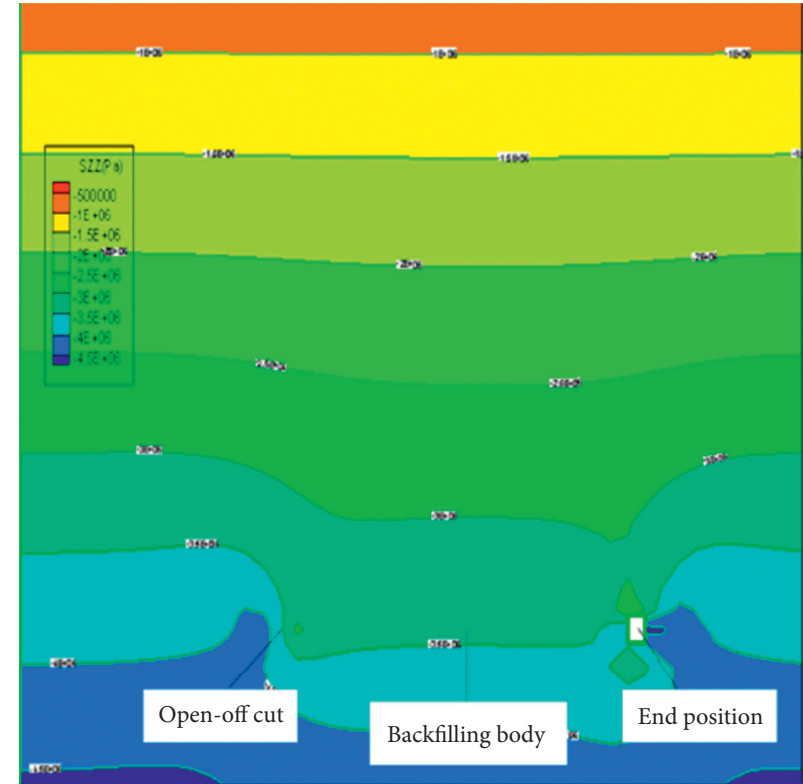

(b)

FIGURE 11: Movement of overlying strata when the working face advances for $100 \mathrm{~m}$ under the elastic modulus of gangue of $5 \mathrm{GPa}$. (a) Displacement vector of surrounding rock. (b) Distribution of vertical stress.

with that under the elastic modulus of $15 \mathrm{GPa}$, the maximum abutment stress changes slightly when the elastic modulus of gangue is $20 \mathrm{GPa}$.

Based on the above analysis, overlying strata during gangue backfilling mining move more gently compared with those in mining with the fully caving method. Strata movement is well controlled and the main roof does not break, but it bends. Because the roof is effectively controlled, the abutment stress of the coal wall and roof subsidence are small. With the gradual increase of the elastic modulus of backfilled gangue, the vertical stress concentration degree constantly decreases. Under the elastic modulus of backfilled gangue of $1 \mathrm{GPa}$, the gangue is of low strength, the compressive deformation of the backfilling body is large, and the 


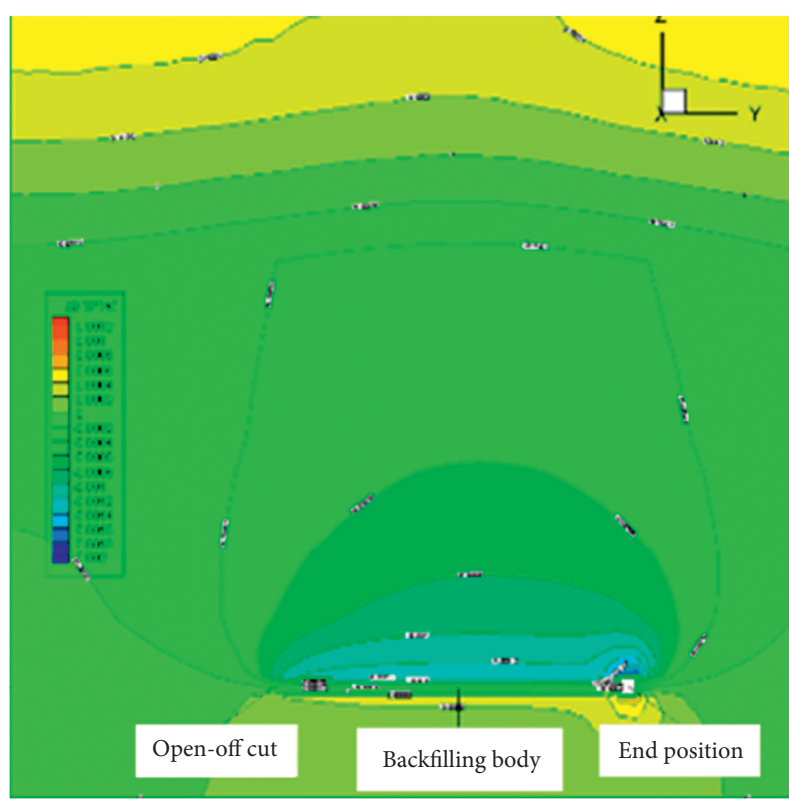

(a)

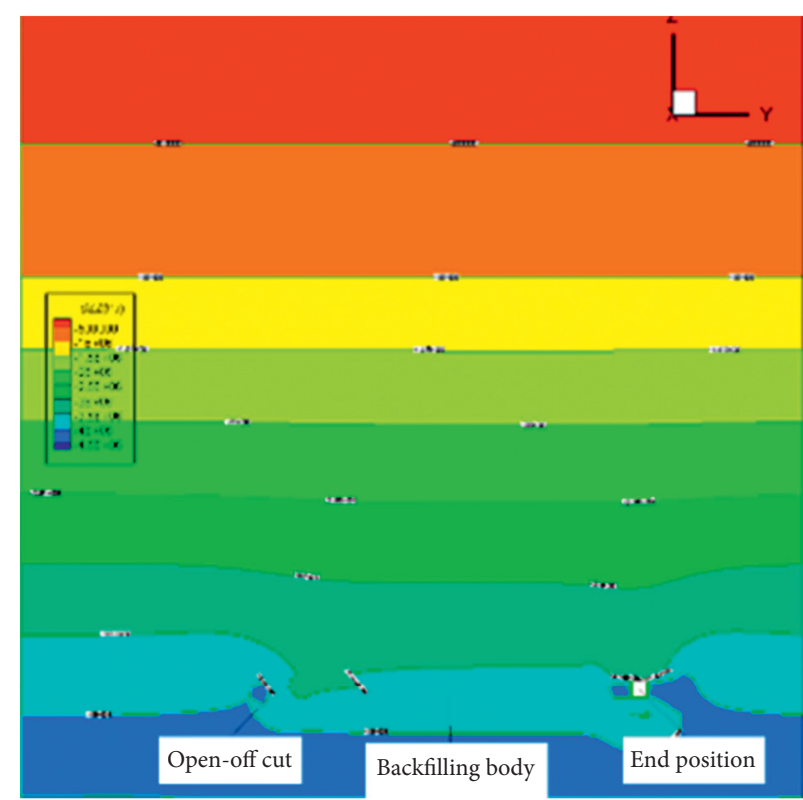

(b)

FigURE 12: Movement of overlying strata when the working face advances for $100 \mathrm{~m}$ under the elastic modulus of gangue of $10 \mathrm{GPa}$. (a) Displacement vector of surrounding rock. (b) Distribution of vertical stress.

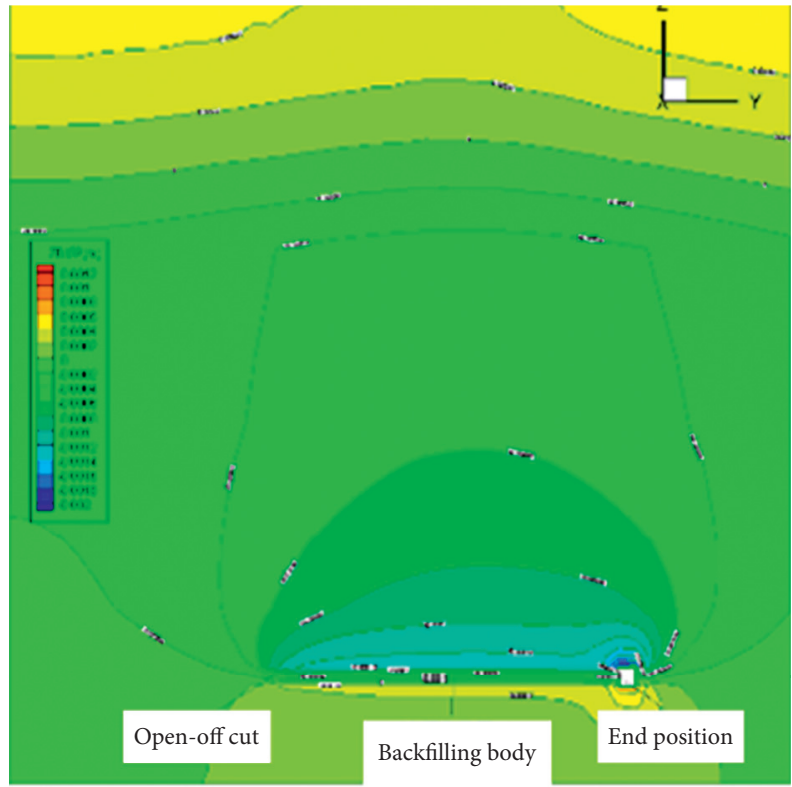

(a)

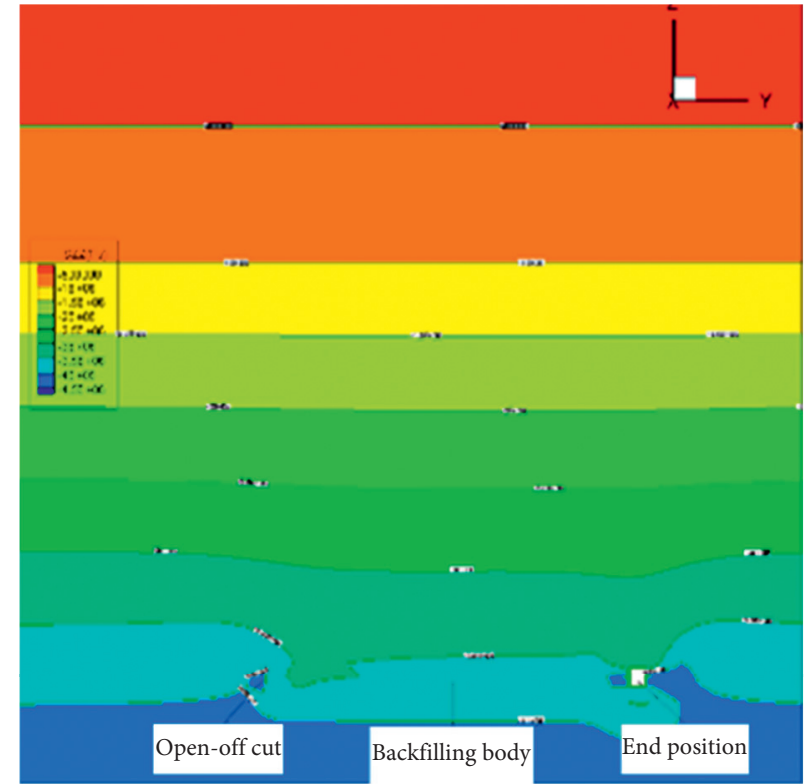

(b)

FIGURE 13: Movement of overlying strata when the working face advances for $100 \mathrm{~m}$ under the elastic modulus of gangue of $15 \mathrm{GPa}$. (a) Displacement vector of surrounding rock. (b) Distribution of vertical stress.

maximum abutment stress in front of the coal wall reaches $25 \mathrm{MPa}$. When the elastic modulus of backfilled gangue rises to $5 \mathrm{GPa}$, the distribution of vertical stress and movement laws of overlying strata are basically same as those under the elastic modulus of $1 \mathrm{GPa}$. However, in this case, the compressive deformation of the backfilling body is obviously small and the vertical stress concentration degree reduces. Furthermore, the maximum abutment stress decreases obviously to $21 \mathrm{MPa}$. As the elastic modulus rises to 10,15 , and $20 \mathrm{GPa}$, movement laws of overlying strata are basically consistent and the vertical stress concentration degree constantly reduces, but its decrease amplitude is not obvious. 


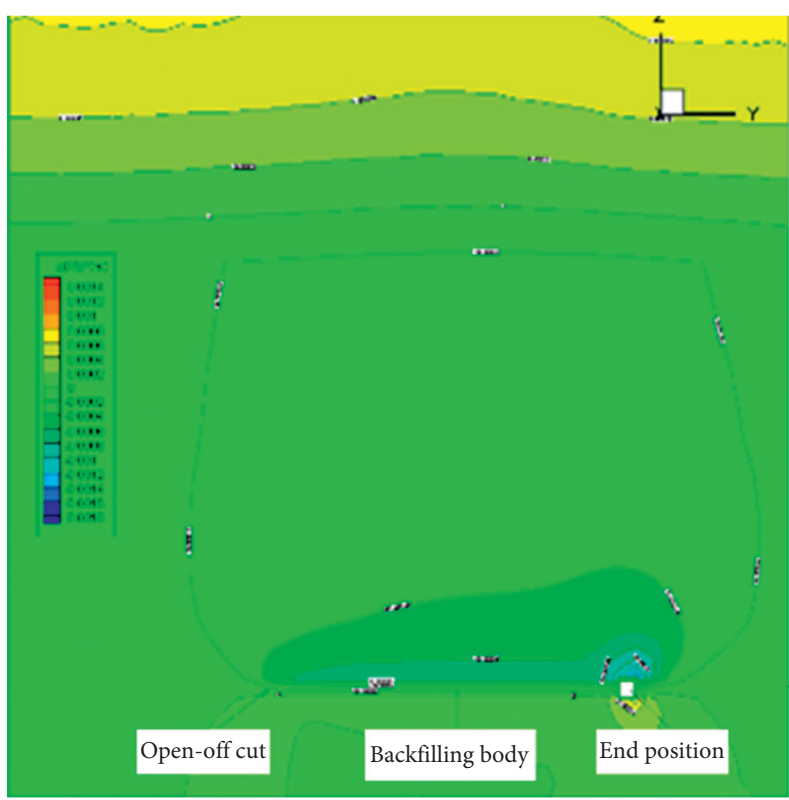

(a)

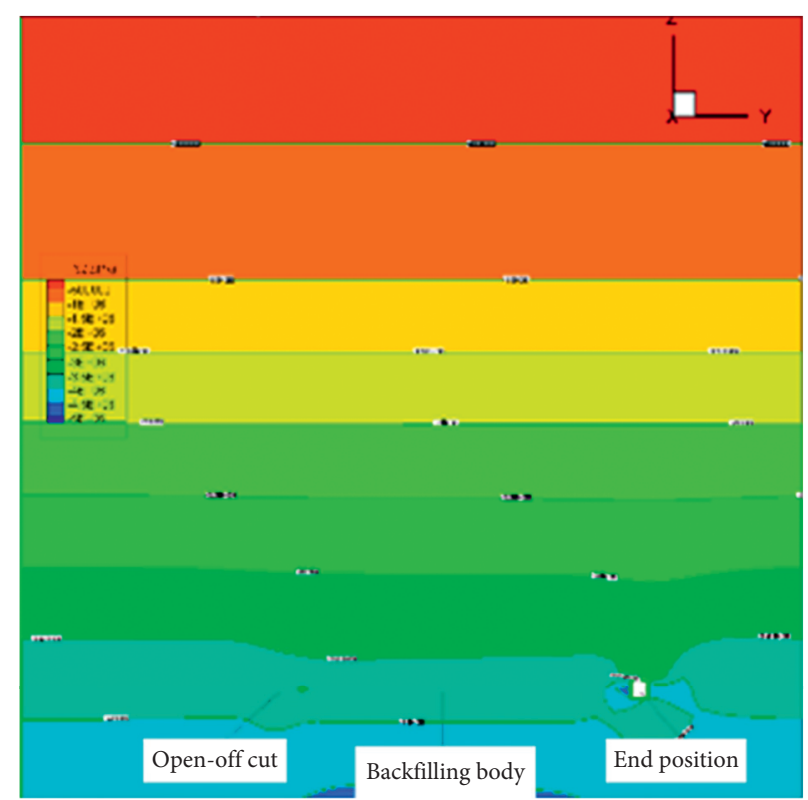

(b)

FIGURE 14: Movement of overlying strata when the working face advances for $100 \mathrm{~m}$ under the elastic modulus of gangue of $20 \mathrm{GPa}$. (a) Displacement vector of surrounding rock. (b) Distribution of vertical stress.

\subsection{Compressive Deformation of the Backfilling Body under} Different Elastic Moduli of Backfilled Gangue. When the elastic moduli of backfilled gangue are 1, 5, 10, 15, and $20 \mathrm{GPa}$, the backfilling body is compressed and deformed under load of overlying strata with the constant advance of the working face, as shown in Figure 15.

As demonstrated in Figure 15, when the elastic moduli of backfilled gangue are $1,5,10,15$, and $20 \mathrm{GPa}$, the maximum compressive deformations of the backfilling body are 215 , $123,66,59$, and $31 \mathrm{~mm}$, respectively. It can be seen from the experiment that, with the gradual increase of the elastic modulus of backfilled gangue, the compressive deformation of the backfilling body continuously decreases, so does its decrease amplitude.

\subsection{Failure Depth of the Floor under Different Elastic Moduli of} Backfilled Gangue. As the elastic moduli of backfilled gangue are $1,5,10,15$, and $20 \mathrm{GPa}$, the failure degrees of the floor under load of overlying strata with the constant advance of the working face are illustrated in Figure 16.

As displayed in Figure 16, under the elastic moduli of backfilled gangue of $1,5,10,15$, and $20 \mathrm{GPa}$, the failure depths of the floor are $44,15,6,5$, and $5 \mathrm{~mm}$, respectively. The experiment shows that the failure depth of the floor and its decrease amplitude constantly reduce as the elastic modulus of backfilled gangue gradually rises. When the elastic modulus of backfilled gangue is $10 \mathrm{GPa}$, the failure depth of the floor is very small and does not change any longer.

5.5. Bending and Subsidence of the Main Roof under Different Elastic Moduli of Backfilled Gangue. By determining the key strata, the main roof of the working face is the key stratum.
Furthermore, through analysis of the mechanical model, it is found that the main roof during gangue backfilling under this condition does not break, but it bends and sinks. When the elastic moduli of backfilled gangue are 1, 5, 10, 15, and $20 \mathrm{GPa}$, the bending and subsidence of the main roof under the load of overlying strata are obtained with the continuous advance of the working face, as displayed in Figure 17.

Figure 18 demonstrates that as the elastic moduli of backfilled gangue are $1,5,10,15$, and $20 \mathrm{GPa}$, the values of bending and subsidence of the main roof are 158, 45, 23, 23, and $11 \mathrm{~mm}$, respectively. It can be observed from the experiment that, with gradual increase of the elastic modulus of backfilled gangue, bending and subsidence of the main roof constantly reduce, so does its decrease amplitude. When the elastic modulus of backfilled gangue is $15 \mathrm{GPa}$, the bending and subsidence of the main roof tend to stabilize, indicating that the strength of backfilled gangue determines the bending and subsidence degree of the key strata.

5.6. Surface Deformation under Different Elastic Moduli of Backfilled Gangue. Under the elastic moduli of backfilled gangue of 1, 5, 10, 15, and $20 \mathrm{GPa}$, Figure 18 shows surface subsidence, inclination deformation, curvature deformation, and horizontal deformation with the constant advance of the working face.

As illustrated in Figure 18(a), when the elastic moduli of backfilled gangue are $1,5,10,15$, and $20 \mathrm{GPa}$, the maximum surface subsidence is $73,27,11,11$, and $5 \mathrm{~mm}$, respectively. The experiment demonstrates that, with the gradual rise of the elastic modulus of backfilled gangue, surface subsidence decreases and its decrease amplitude reduces constantly. Even if the elastic modulus of backfilled gangue is $1 \mathrm{GPa}$, the maximum surface subsidence is only $73 \mathrm{~mm}$, which is very 
Distance from the open-off cut (m)

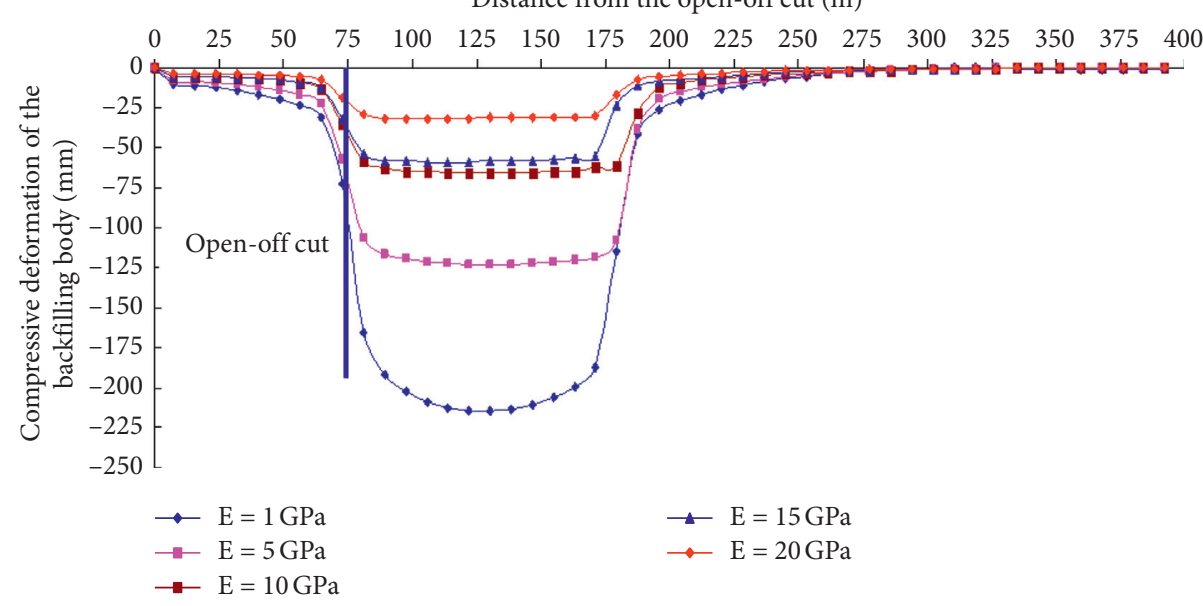

Figure 15: Compressive deformation of the backfilling body.

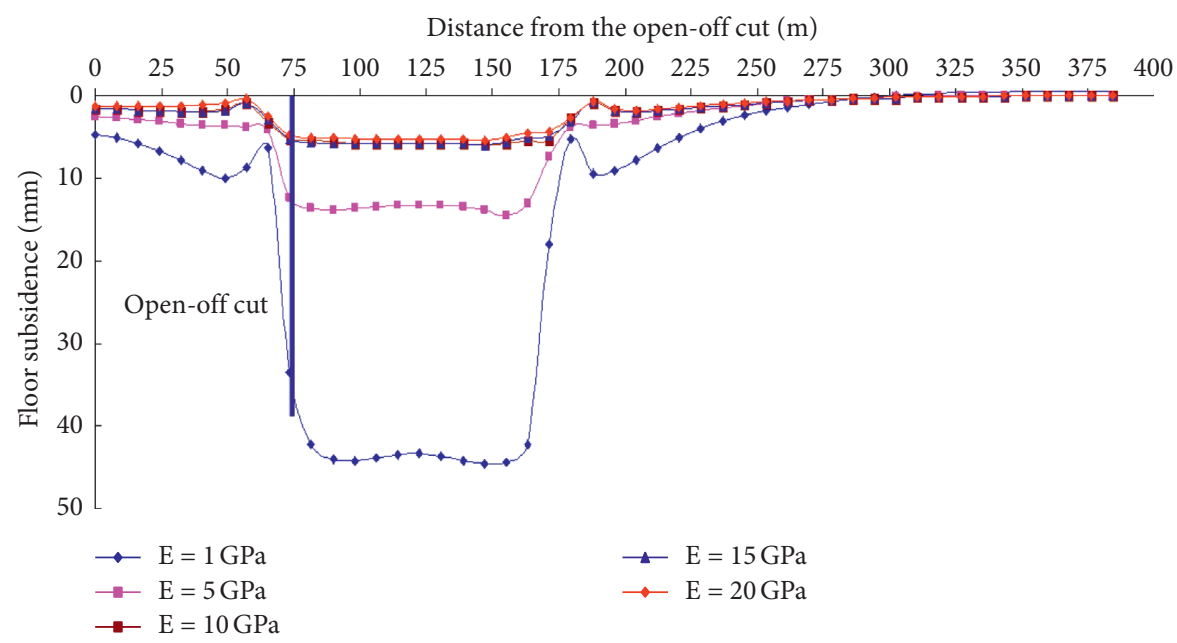

Figure 16: Failure depth of the floor.

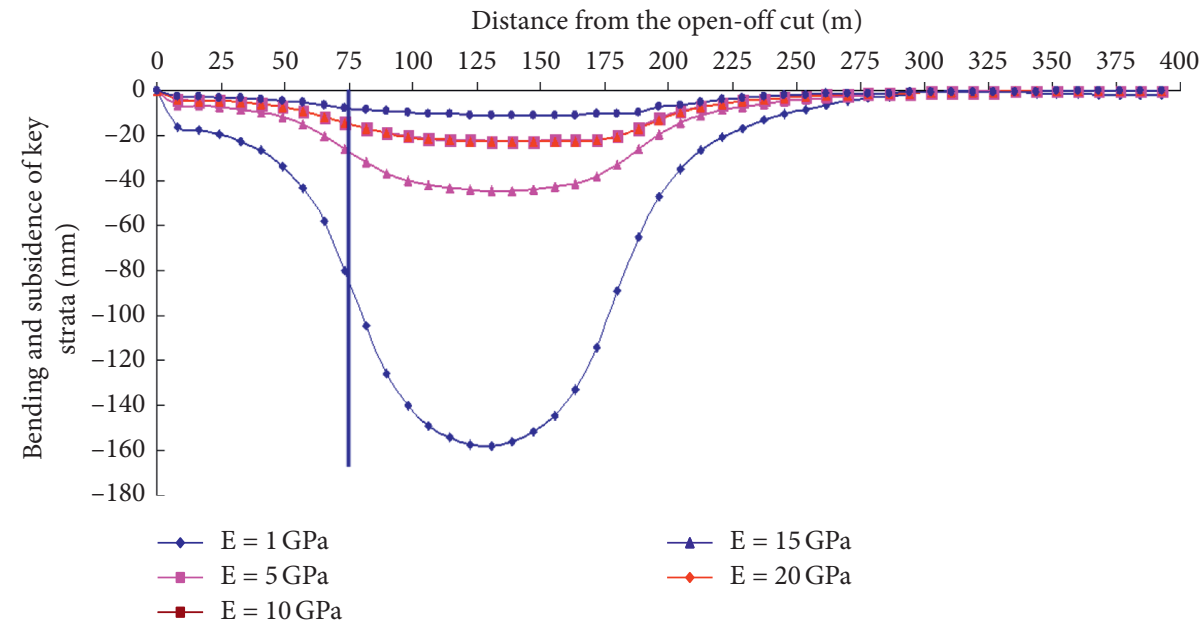

FIGURE 17: Bending and subsidence of the main roof. 


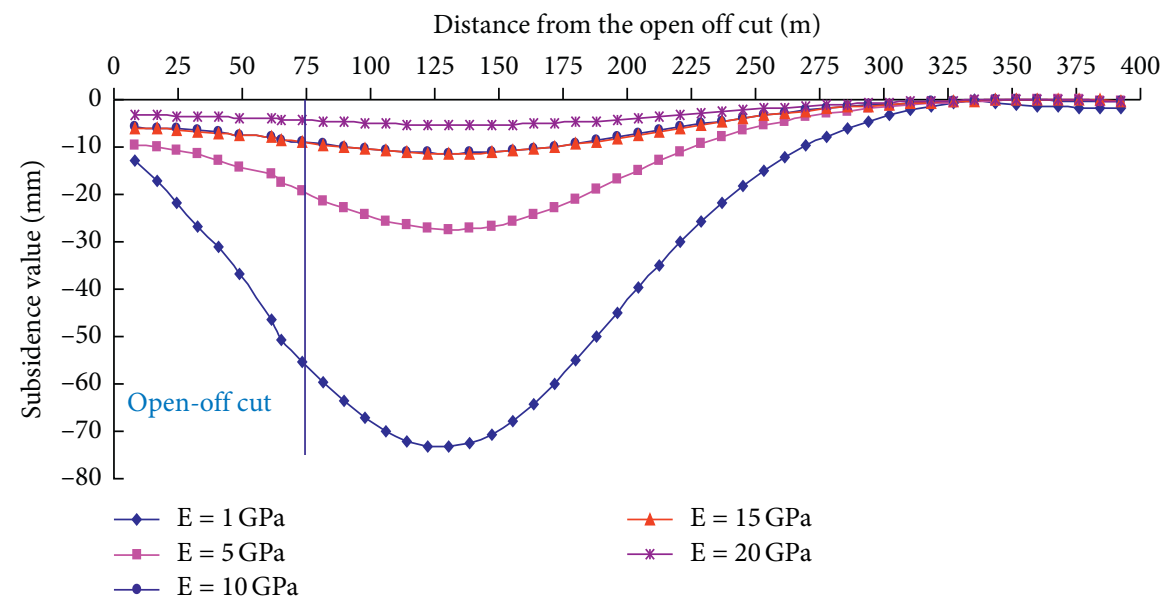

(a)

Distance from the open-off cut (m)

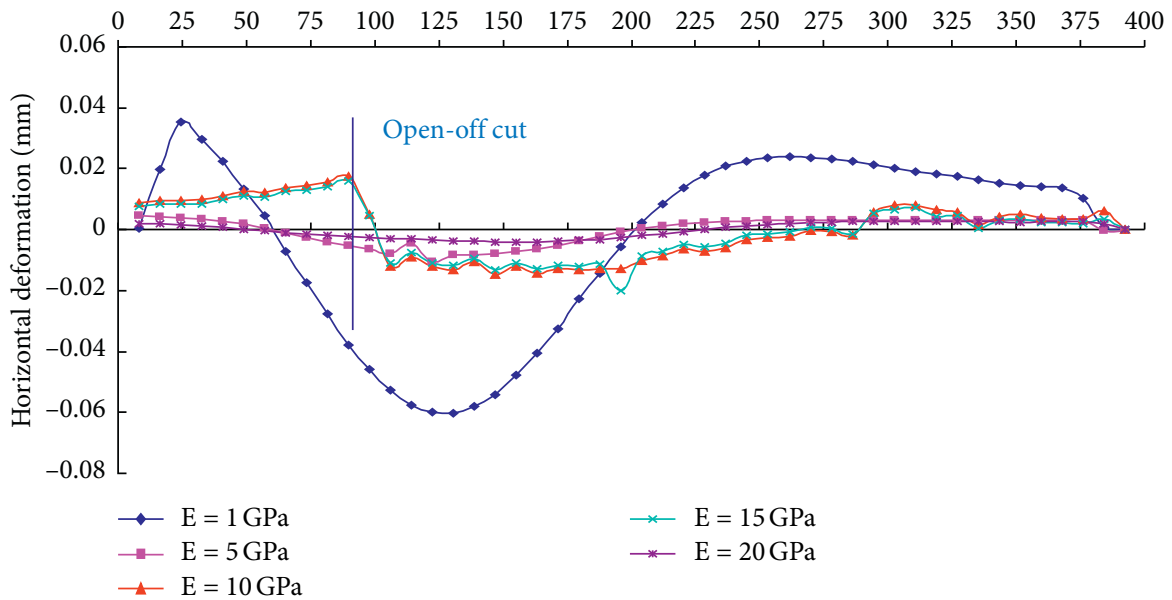

(b)

Distance from the open-off cut (m)

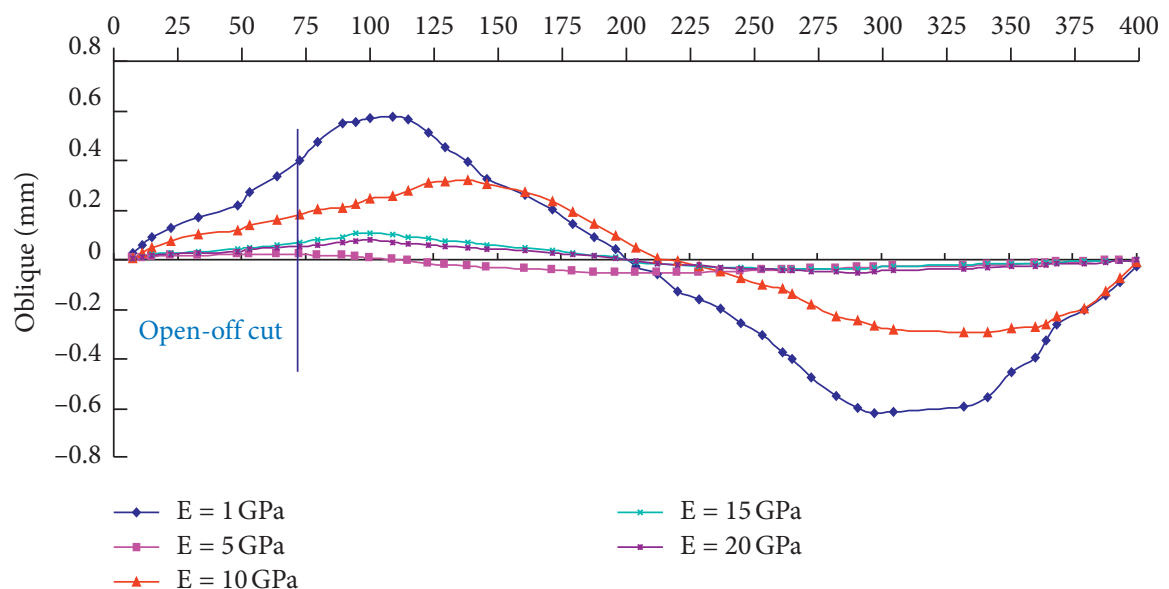

(c)

Figure 18: Continued. 


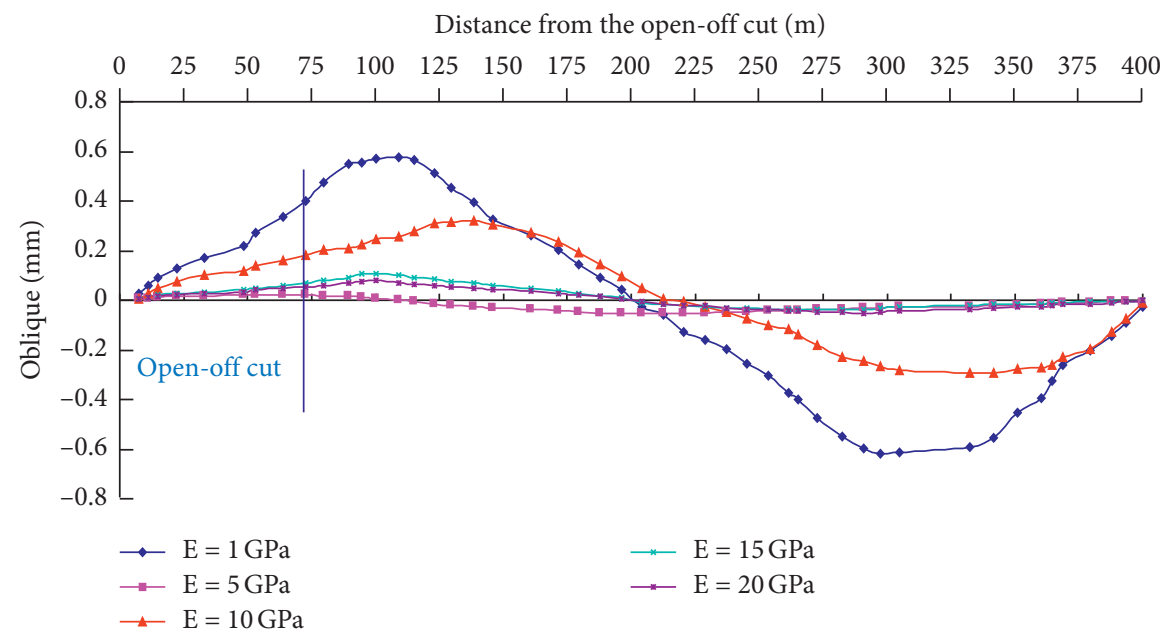

(d)

FIGURE 18: Surface deformation laws under different elastic moduli of backfilled gangue. (a) Surface subsidence. (b) Horizontal deformation. (c) Curvature deformation. (d) Inclination deformation.

small compared with that in the traditional mining, so it has a little effect on surface buildings. Under the elastic modulus of backfilled gangue of $10 \mathrm{GPa}$, surface subsidence basically tends to be stable. The horizontal, inclination, and curvature laws are basically consistent with surface subsidence laws.

\section{Conclusions}

Firstly, this study determined the stress distribution characteristics in the stope of the gangue backfilling face based on thin-plate theory and then conducted a theoretical analysis to determine stress distribution characteristics in overlying strata. Secondly, the key strata above the working face backfilled with gangue were determined and the deformation characteristics of the roof disturbed by mining were ascertained. Finally, this research analyzed gangue with different elastic moduli, clarified effects of mechanical parameters of gangue on surface subsidence, and determined reasonable physical and mechanical parameters of gangue. The main conclusions are made as follows:

(1) Stress distribution laws in the main roof of the fully mechanized coal mining face backfilled with gangue in a coal seam in Jiulishan Coal Mine were analyzed based on thin-plate theory. Based on this, the position of the main roof first bending and sinking under load of overlying strata was obtained. By using the determination method based on the key stratum theory, it was concluded that there were two key strata and the main roof belonged to the inferior key stratum.

(2) This study established the mechanical model of the main roof of the fully mechanized coal mining face backfilled with gangue and the calculation formula for the maximum deflection of the main roof and presented the conditions for breaking of the main roof. Based on the theoretical analysis, it was concluded that the main roof of the fully mechanized coal mining face backfilled with gangue did not break but bent.

(3) Based on strain-hardening characteristics of the FLAC $^{3 D}$ software for numerical simulation, the strata movement under mining by backfilling with different strengths of gangue was numerically simulated. The research showed that, in the process of the elastic modulus of backfilled gangue increasing from 1 to $20 \mathrm{GPa}$, the maximum compressive deformation of the backfilling body reduced from 215 to $31 \mathrm{~mm}$ and the failure depth of the floor decreased from 44 to $5 \mathrm{~mm}$. Moreover, the bending and subsidence of the main roof dropped from 158 to $11 \mathrm{~mm}$. It was also concluded that, with the constant increase of strength of backfilled gangue, the stress concentration degree of surrounding rock continuously reduced, so did the decrease amplitude. Furthermore, the compressive deformation of the backfilling body, failure depth of the floor, and bending and subsidence of the main roof constantly reduced and tended to be stable. This revealed dynamic change laws of strata movement above the fully mechanized coal mining face backfilled with gangue.

(4) Horizontal, inclination, and curvature deformation laws were basically consistent with surface subsidence laws. When the elastic moduli of backfilled gangue were 1 and $20 \mathrm{GPa}$, the maximum surface subsidence was 73 and $5 \mathrm{~mm}$, respectively. With the gradual increase of the elastic modulus of backfilled gangue, surface subsidence decreased and its decrease amplitude constantly reduced. Even if the elastic modulus of backfilled gangue was $1 \mathrm{GPa}$, the maximum surface subsidence was only $73 \mathrm{~mm}$, which was very small compared with that in the traditional mining, so it had very little impact on surface buildings. As the elastic modulus of 
backfilled gangue was $10 \mathrm{GPa}$, the surface subsidence basically was inclined to be stable. It was concluded that backfilling materials determined the effects of gangue backfilling technology in controlling surface subsidence and that gangue backfilling effectively controlled strata movement.

\section{Data Availability}

All the data have been included in the manuscript.

\section{Conflicts of Interest}

The authors declare that they have no conflicts of interest.

\section{Acknowledgments}

This work was financially supported by National Natural Science Foundation of China (52074120, 51904303, and 51774110), Program for Science \& Technology Innovation Talents in Universities of Henan Province (19HASTIT047), and Science and Technology Project of Henan Province (182102310012), which are gratefully acknowledged.

\section{References}

[1] H. U. Bingnan, "Backfill mining technology and development tendency in China coal mine," Coal Science and Technology, vol. $40,2012$.

[2] L. I. Jianping, K. Zheng, and D. U. Changlong, "The distribution discipline of impact crushed on coal and gangue," Journal of china University of Mining \& Technology, vol. 38, 2013.

[3] J. Li, C. Du, and L. Xu, "Impactive crushing and separation experiment of coal and gangue," Journal of China Coal Society, vol. 32, 2011.

[4] X. Miao, "Principle of underground pressure control in fullymechanized coal mining with solid filing and force analysis of mining support," Journal of china University of Mining \& Technology, vol. 6, 2010.

[5] X. Miao and M. Qian, "Research on green mining of coal resources in China current status and future prospects," Journal of Mining \& Safety Engineering, vol. 26, pp. 1-14, 2009.

[6] J. Zhang, J. Li, T. An et al., "Deformation characteristics of key stratum overburden by raw waste backfilling with fullymechanized coal mining technology," Journal of China Coal Society, vol. 35, no. 3, pp. 357-362, 2010.

[7] K. Zheng, C. Du, and B. Qiu, "Experimental study on the fractal characteristics of crushing coal and gangue," Journal of china University of Mining \& Technology, vol. 25, 2013.

[8] Y.-B. Jung, S. Won-Kyong, C. Dae-Sung et al., "Simple method for the identification of subsidence susceptibility above underground coal mines in Korea," Engineering Geology, vol. 178, 2014.

[9] L. Li, A. Tang, D. Zhao et al., "Block caving-induced strata movement and associated surface subsidence: a numerical study based on a demonstration model," Bulletin of Engineering Geology and the Environment, vol. 73, no. 4, pp. 1165-1182, 2014.

[10] M. Nazem and M. Karakus, "Numerical analysis of a large landslide induced by coal mining subsidence," Engineering Geology, vol. 217, 2017.
[11] W. Kyu-Seok, E. Erik, E. Davide et al., "Empirical investigation and characterization of surface subsidence related to block cave mining," International Journal of Rock Mechanics and Mining Sciences, vol. 61, 2013.

[12] Q. Zou, H. Liu, Z. Cheng, T. Zhang, and B. Lin, "Effect of slot inclination angle and borehole-slot ratio on mechanical property of pre-cracked coal: implications for ECBM recovery using hydraulic slotting," Natural Resources Research, vol. 29, pp. 1705-1729, 2020.

[13] Z. Quanle and L. Baiquan, "Fluid-solid coupling characteristics of gas-bearing coal subject to hydraulic slotting: an experimental investigation," Energy \& Fuels, vol. 32, pp. 1047-1060, 2018.

[14] G. U. O. Guangli, W. FENG, Z. H. A. Jianfeng et al., "Subsidence control and farmland conservation by solid backfilling mining technology," Transactions of Nonferrous Metals Society of China, vol. 21, no. s1, pp. s665-s669, 2011.

[15] M. I. A. O. Xiexing, "Review of research on mechanical behavior of mining rock mass and its related engineering technology innovation progress Chinese," Journal of Rock Mechanics and Engineering, vol. 29, 2010.

[16] M. I. A. O. Xiexing, "Progress of fully mechanized mining with solid backfilling technology," Journal of China Coal Society, vol. 37, 2012.

[17] J. Lou, F. Gao, J. Yang et al., "Characteristics of evolution of mining-induced stress field in the longwall panel: insights from physical modeling," International Journal of Coal Science \& Technology, 2021.

[18] D. Ritesh Lokhande, M. S. R. Murthy Vemavarapu, V. Vellanky et al., "Assessment of pot-hole subsidence risk for Indian coal mines," International Journal of Mining Science and Technology, vol. 25, 2015.

[19] Z. Quanle, L. Baiquan, C. Zheng et al., "Novel integrated techniques of drilling-slotting-separation-sealing for enhanced coal bed methane recovery in underground coal mines," Ournal of Natural Gas Science and Engineering, vol. 26, 2015.

[20] G. Guo, J. Zha, X. Miao et al., "Similar material and numerical simulation of strata movement laws with long wall fully mechanized gangue backfilling," Procedia Earth and Planetary Science, vol. 1, 2009.

[21] J. Wang, Y. A. N. G. Shengli, Y. A. N. G. Baogui et al., "Simulation experiment of overlying strata movement features of longwall with gangue backfill mining," Journal of China Coal Society, vol. 37, 2012.

[22] Q. Wang, G. U. O. Guangli, Z. H. A. Jianfeng et al., "Study on surface ground movement law of coal rejects backfill mining under thick and loose overburden strata," Coal Science and Technology, vol. 41, 2013.

[23] J. Zhang, Q. Wu, Y. Huang et al., "Strata pressure behavior by raw waste backfilling with fully-mechanized coal mining technology," Journal of China Coal Society, vol. 34, 2010.

[24] D. Kong, Z. B. Cheng, and S. S. Zheng, "Study on the failure mechanism and stability control measures in a large-cuttingheight coal mining face with a deep-buried seam," Bulletin of Engineering Geology and the Environment, vol. 78, pp. 61436157, 2019.

[25] J. Ju and J. Xu, "Surface stepped subsidence related to top-coal caving longwall mining of extremely thick coal seam under shallow cover," International Journal of Rock Mechanics and Mining Sciences, vol. 78, 2015.

[26] Q. L. Zou, Y. Zhang, Q. Li, J. Fu, and Q. Hu, "Rationality evaluation of production deployment of outburst-prone coal 
mines: a case study of nantong coal mine in Chongqing, China," Safety Science, vol. 122, 2020.

[27] I. D. Brunton, S. J. Fraser, J. H. Hodgkinson et al., "Parameters influencing full scale sublevel caving material recovery at the Ridgeway gold mine," International Journal of Rock Mechanics and Mining Sciences, vol. 47, 2009.

[28] Q. Hu, X. Deng, R. Feng et al., "Model for calculating the parameter of the Knothe time function based on angle of full subsidence," International Journal of Rock Mechanics and Mining Sciences, vol. 78, 2015.

[29] I. A. M. Suchowerska, J. P. Carter, and J. P. Hambleton, "Geomechanics of subsidence above single and multi-seam coal mining," Journal of Rock Mechanics and Geotechnical Engineering, vol. 8, 2016.

[30] M. Karmis, Z. Agioutantis, and A. Jarosz, "Recent developments in the application of the influence function method for ground movement predictions in the U.S," Mining Science and Technology, vol. 10, 1990.

[31] Q. Zhang, J. Zhang, S. Guo et al., "Design and application of solid, dense backfill advanced mining technology with two pre-driving entries," International Journal of Mining Science and Technology, vol. 25, 2015.

[32] T. Sasaoka, H. Takamoto, H. Shimada et al., "Surface subsidence due to underground mining operation under weak geological condition in Indonesia," Journal of Rock Mechanics and Geotechnical Engineering, vol. 7, 2015.

[33] V. Palchik, "Experimental investigation of apertures of mining-induced horizontal fractures," International Journal of Rock Mechanics and Mining Sciences, vol. 47, 2009.

[34] J.-A. Wang, H. D. Park, and Y. T. Gao, "A new technique for repairing and controlling large-scale collapse in the main transportation shaft, Chengchao iron mine, China," International Journal of Rock Mechanics and Mining Sciences, vol. 40, 2003.

[35] Y. Luo, "An improved influence function method for predicting subsidence caused by longwall mining operations in inclined coal seams," International Journal of Coal Science \& Technology, vol. 2, pp. 163-169, 2015.

[36] J. Zhang, Q. Zhang, Q. Sun et al., "Surface subsidence control theory and application to backfill coal mining technology," Environmental Earth Sciences, vol. 74, pp. 1439-1448, 2015.

[37] J. F. Lupo, "Large-scale surface disturbances resulting from underground mass mining," International Journal of Rock Mechanics and Mining Sciences, vol. 16, 1998.

[38] H. E. Zhexiang, N. Wang, and C. Xie, "Analysis of surrounding rock activities partial backfill mining," Journal of China University of Mining \& Technology, vol. 33, 2004.

[39] H. Liang: Integrated Technology of Backfill Mining and Raw Coal Separation in Underground Mine Coal Science and Technology 2013.

[40] H. U. Bingnan and G. U. O. Aiguo, "Testing study on coal waste back filling material compression simulation," Journal of china University of Mining \& Technology, vol. 34, no. 8, pp. 1076-1080, 2009.

[41] X. Huang, L. Tao, and W. Cao, Rock Mechanics, Higher Education Press, Beijing, China, 2005.

[42] M. A. Zhanguo, G. U. O. Guangli, R. Chen et al., "An experimental study on the compaction of water-saturated over broken rock," Chinese Journal of Rock Mechanics and Engineering, vol. 24, no. 7, pp. 1139-1144, 2005.

[43] D. O. N. G. Shouyi, "Analysis and practices on integrated match of backfill mining equipment," Coal Science and Technology, vol. 40, 2012.
[44] H. Zhang, X. Zhang, and C. A. O. Zhong: Research on Physical and Mechanical Characteristics of Refuse Rock in Filling Coal Mining Technology 2008.

[45] P Helm, C T Davie, and S Glendinning, "Numerical modelling of shallow abandoned mine working subsidence affecting transport infrastructure," Engineering Geology, vol. 154, 2013.

[46] J. Liu and Z. Qingbiao, "Comprehensive mechanized filling coal mining," Journal of China Coal Society, vol. 35, 2010.

[47] G. Guangli, X. Zhu, Z. Jianfeng et al., "Subsidence prediction method based on equivalent mining height theory for solid backfilling mining," Transactions of Nonferrous Metals Society of China, vol. 24, 2014.

[48] F. Wang, B. Jiang, S. Chen et al., "Surface collapse control under thick unconsolidated layers by backfilling strip mining in coal mines," International Journal of Rock Mechanics and Mining Sciences, vol. 113, 2019.

[49] L. Shuncai, Z. Chen, and L. Yu, "Study on penetration features of coal rejects during constant load deformation test process," Coal Science and Technology, vol. 41, 2013.

[50] X. Jialin and Q. Minggao, "Application research and practice of rock formation control key layer theory," China Mining, vol. 13, 2001.

[51] X. Zhu, G. Guo, J. Zha et al., "Surface dynamic subsidence prediction model of solid backfill mining," Environmental Earth Sciences, vol. 75, 2016.

[52] W. Xie, Z. Shi, X. Chen et al., "Analysis of surrounding rock activities in partial backfill mining," Journal of China University of Mining \& Technology, vol. 33, 2004.

[53] J. Xu, M. Qian, W. Ma et al., "Discussion on loading problem in physical and numerical simulation of strata movement," Journal of China University of Mining \& Technology, vol. 30, 2001. 